NBER WORKING PAPER SERIES

\title{
AUTOPSY ON AN EMPIRE: UNDERSTANDING MORTALITY IN RUSSIA AND THE FORMER SOVIET UNION
}

\author{
Elizabeth Brainerd \\ David M. Cutler \\ Working Paper 10868 \\ http://www.nber.org/papers/w10868
NATIONAL BUREAU OF ECONOMIC RESEARCH
1050 Massachusetts Avenue
Cambridge, MA 02138
October 2004

David Cutler is grateful to the National Institutes on Aging for research support. Elizabeth Brainerd's research for this paper was supported in part through Grant Number S-LMAQM-00-H-0146 provided by the United States Department of State and administered by the William Davidson Institute, University of Michigan. David Cutler's research is supported by the National Institutes on Aging. The opinions, findings and conclusions or recommendations expressed herein are those of the author(s) and do not necessarily reflect those of any of the sponsoring organizations. The views expressed herein are those of the author(s) and not necessarily those of the National Bureau of Economic Research.

(C2004 by Elizabeth Brainerd and David M. Cutler. All rights reserved. Short sections of text, not to exceed two paragraphs, may be quoted without explicit permission provided that full credit, including $\odot$ notice, is given to the source. 
Theoretical Foundation of Buffer Stock Saving

Elizabeth Brainerd and David M. Cutler

NBER Working Paper No. 10868

October 2004

JEL No. I1, P0

\begin{abstract}
$\underline{\text { ABSTRACT }}$
Male life expectancy at birth fell by over six years in Russia between 1989 and 1994. Many other countries of the former Soviet Union saw similar declines, and female life expectancy fell as well. Using cross-country and Russian household survey data, we assess six possible explanations for this upsurge in mortality. Most find little support in the data: the deterioration of the health care system, changes in diet and obesity, and material deprivation fail to explain the increase in mortality rates. The two factors that do appear to be important are alcohol consumption, especially as it relates to external causes of death (homicide, suicide, and accidents) and stress associated with a poor outlook for the future. However, a large residual remains to be explained.

Elizabeth Brainerd

Department of Economics

Williams College

Williamstown, MA 01267

elizabeth.brainerd@williams.edu

David M. Cutler

Department of Economics

Harvard University

Cambridge, MA 02138

and NBER

dcutler@harvard.edu
\end{abstract}


The 1990s were a decade of turmoil for the formerly socialist countries. Besides the political, economic and social upheavals endured by these populations, many of these countries also experienced a demographic disaster in the form of sharply rising death rates. In Russia, male life expectancy at birth fell from 64.2 years in 1989 to 57.6 years in 1994, a decline of 6.6 years in just half a decade. Female life expectancy at birth fell by 3.3 years over the same time period. To put this in perspective, it took the past 30 years for the United States to increase life expectancy by this much. Russia's life expectancy today ranks $122^{\text {nd }}$ in the world, at the same level as North Korea and Guyana.

The mortality crisis is not limited to Russia. Across the western countries of the former Soviet Union - the countries which we term 'the mortality belt' and which range from Estonia in the north to Ukraine in the south - there have been significant declines in male life expectancy at birth, ranging from 3.3 years (Belarus) to nearly 5 years in Estonia and Latvia (see Figure 1). Life expectancy for women fell substantially as well.

But not all countries fared this poorly. The countries which directly border this 'mortality belt' and which also experienced a severe economic shock in the 1990s - Poland, the Czech and Slovak Republics, Hungary, and Romania - recorded negligible increases in mortality rates during their transition from communism, and since the mid-1990s many of these countries have enjoyed the fastest increases in life expectancy recorded in their recent history.

Understanding why mortality in Russia and many of its neighboring countries increased so rapidly is a central research and policy question. Analysts of the Russian experience, for example, describe the mortality profile as the most puzzling aspect of the Russian transition (Shleifer and Treisman 2003). A number of theories have been put forward about the mortality crisis: the breakdown of the medical care system (Ellman 1994); increased alcohol consumption 
(Leon et al. 1997); a reduction in material living standards, as reflected in diet and nutrition (Field 1995); increased stress from the economic transition (Shapiro 1995; Cornia and Paniccià 2000); and a reduced outlook for the future (Watson 1995).

Some progress on understanding the mortality crisis has been made by researchers. Epidemiologists have studied Russian mortality data at the national level to decompose changes in death rates by cause of death and age group (Leon et al. 1997; Shkolnikov et al. 2001a) and have interviewed relatives of deceased men to identify characteristics associated with an increased probability of dying (Shkolnikov et al. 2001b). Medical researchers have examined the prevalence of biological risk factors for cardiovascular disease in Russia and other countries of the former Soviet Union (Kristenson et al. 1997; Puska et al. 1993; Stegmayr et al. 2000), and have studied the course of epidemic diseases across Russia and the response of the health system to these epidemics (Vitek et al. 1999; Kalichman et al. 2000).

Using these findings and our own analysis of cross-country and Russian survey data, we discuss and analyze possible causes of the mortality crisis in the former Soviet Union, as well as the equally puzzling dramatic improvement in mortality rates in the late 1990s in most countries.

We begin by describing the overall trends in death rates in the region, providing an overview of changes in mortality by region, age and cause. Russia is not unique: other former Soviet countries experienced changes in mortality remarkably similar to those of Russia during the transition period. Moreover, virtually every country in Eastern Europe and the former Soviet Union experienced at least a short-term increase in death rates among certain demographic groups. But Russia is different in that the mortality crisis is particularly acute among prime age men - not the elderly or infants, the groups most commonly thought to be at risk because of economic change. 
We next explore the possible causes of the dramatic swings in mortality across the region, focusing on six broad factors: changes in the health care system; traditional risk factors such as obesity and smoking; increased alcohol consumption; changes in the composition of the diet; material deprivation; and levels of stress and changing expectations about the future. Several factors are easy to dispose of. Although the medical system in the former Soviet Union deteriorated significantly, we find no evidence that this deterioration played a major role in the demographic disaster. Nor is smoking, obesity, or undernutrition the problem.

In the end, our results point to two factors as being most important, alcohol, especially as it relates to external causes of death (homicide, suicide, and accidents) and stress associated with a poor outlook for the future. We find that these two factors are of roughly equal importance in accounting for the dramatic increase in mortality in Russia - though we caution that there is still a large residual to be explained.

\section{Mortality trends in the Former Soviet Union}

We start off by examining mortality trends in Russia and the former Soviet Union. The obvious question that arises in any analysis of the former Soviet Union is data quality. Many statistics about the former Soviet bloc are not reliable. Demographic data are believed to be an exception, however: registration of vital events is nearly complete, and the coding of broad categories of death is reasonably accurate (Anderson and Silver 1997; Shkolnikov et al. 1997; Shkolnikov et al. 1999; Shkolnikov et al. 2002). As a result, there is widespread agreement among demographers and epidemiologists that the fluctuations in mortality rates we describe are 
real and do not reflect a radical change in the vital registration system. ${ }^{1}$

Figure 2 illustrates the erratic changes in life expectancy experienced in most countries of the former Soviet Union in recent years, in contrast to the slowly evolving changes in life expectancy recorded in the United States and other industrialized countries. The top panel (Figure 2a) shows life expectancy for the mortality belt countries. ${ }^{2}$ By the early 1960 s life expectancy in the Soviet Union had nearly reached that of the United States - within 3 years. Mortality failed to improve over the next decade, however, and a large East-West life expectancy gap emerged. By 1980, the difference in life expectancy was nearly 8 years.

The post-1984 period is marked by large swings in life expectancy. There was a striking improvement in mortality during Gorbachev's anti-alcohol campaign (1985-1987), when life expectancy increased nearly three years.

From there, however, the situation deteriorated dramatically. The deterioration began in earnest in 1990 and lasted until the mid-1990s, coincident with the period of greatest economic, political, and social instability in most countries. The 6 year reduction in male life expectancy at birth in Russia between 1989 and 1994 is almost unprecedented in its speed and scope, though it was nearly matched by the declines in life expectancy in many of Russia's western neighbors. Over the same period, male life expectancy fell by 4.6 years in Estonia, 4.5 years in Latvia, 4.2 years in Lithuania, and 3.7 and 3.3 years, respectively, in Ukraine and Belarus.

\footnotetext{
${ }^{1}$ Despite the generally high quality of the demographic data in the region, however, it should be noted that the mortality data are less reliable in some countries of Central Asia and the Caucuses. Inconsistencies in the reporting of deaths at the oldest ages have been reported in some countries, and Georgia implemented a fee for death registration in the early 1990s, which likely led to underreporting of deaths (Badurashvili et al. 2001). Data for these countries should be interpreted with caution.

${ }^{2}$ Figure 2a omits Latvia to reduce clutter; the level and change in male life expectancy in Latvia is nearly identical to that of Estonia. Male and female life expectancy for all transition countries are shown in Appendix Figure 1. All data prior to 1991 are for the Soviet republics individually rather than for the USSR as a whole.
} 
After 1994, the situation began to improve. Between 1994 and 1998, life expectancy in Russia increased by over 3 years. Most of the gains were eroded, however, following Russia's 1998 financial crisis; male life expectancy has fallen continually from peak of 61.3 years in 1998 to only 58.5 years in 2002 .

Figure $2 \mathrm{~b}$ shows mortality in the Central Asian republics. Life expectancy fell in these countries as well, but the declines were neither as dramatic nor long-lasting as in the western former Soviet Union. Kazakhstan registered the largest decline in life expectancy in this group, with male life expectancy at birth falling by five years between 1989 and 1996; the smallest decline in this region occurred in Uzbekistan, where male life expectancy fell by 1.6 years between 1990 and 1994. ${ }^{3}$ Among the three Caucuses countries - Armenia, Azerbaijan, and Georgia - declines in life expectancy ranged from 1.6 years (Armenia) to 4.2 years (Azerbaijan) in the early 1990s.

Remarkably, despite substantial declines in per capita income, rising unemployment, and a wide range of reform experiences, none of the East European countries experienced a prolonged decline in life expectancy in the 1990s, and some did not see any material setback (Figure 2c). The most successful economic reformers - the Czech Republic, Poland, Hungary, and Slovenia - registered near-continual increases in life expectancy since the start of their reforms. This differs not only with the neighboring 'mortality belt' countries, but also with the experience of the previous three decades, in which life expectancy stagnated in a pattern similar to that of the Soviet Union. Life expectancy fell in Bulgaria and Romania, but these declines are small relative to those that occurred in the western region of the former Soviet Union.

\footnotetext{
${ }^{3}$ Tajikistan is omitted from the analysis in this paper due to the civil war that plagued the country in the early 1990s, and which led to a decline in male life expectancy from 66 to 56 years between 1992 and 1993. The quality of the demographic data in Tajikistan is also considered to be relatively poor.
} 
In the Appendix, we show similar figures for female life expectancy at birth. The patterns are very similar, although the magnitude of the changes is smaller.

Changes in mortality are clearly related to the economic health of the country. Figure 3 shows the relation in more detail: we relate the log change in age-standardized male mortality between 1989 and 1994 to the log change in real per capita GDP over the same time period. ${ }^{4}$ The two are highly related (the correlation coefficient is -.60). Countries like Ukraine with poor economic growth had very large increases in mortality. Poland, the Czech Republic, and Slovenia are on the opposite end. Even in the context of this relationship, however, Russia is an outlier: mortality increased more than could be expected given the change in reported GDP, and the mortality increase is even more extreme if the decline in Russia's GDP is substantially overstated as is likely to be the case (Shleifer and Treisman 2003). The relationship between mortality change and GDP growth is less true over the subsequent years of the $1990 \mathrm{~s}$, as the second panel in Figure 3 details. The correlation between mortality change in the 1994 to 2000 period and economic growth over the same period is only -.13. All told, over the entire 1989 to 2000 era, the correlation between reported mortality changes and GDP growth is -.55 .

The strong correlation between mortality change and economic growth begs a more detailed analysis. What are the economic mechanisms that underlie the strong link between economic growth and health? Why did the relationship get weaker over time? Any why is Russia still such an outlier? These are the questions we proceed to examine.

\section{Deaths by Age, Cause, and Socioeconomic Status}

${ }^{4}$ There are substantial issues involved in measuring output changes across countries (Shleifer and Treisman 2003). It would be better to use a measure other than official GDP, but we do not have the data for all countries to do this. For several countries GDP data are missing for 1989, so Figure 3 uses 1990 data instead. Georgia, Bosnia-Herzegovina, FYR Macedonia, and Serbia are omitted due to missing data. 
As a start in understanding why mortality rose so rapidly, we present some more disaggregated information on mortality in Russia; trends for the other mortality belt countries are reported in the Appendix, and look similar. We look at the period from 1989 to 1994, the years of the largest increase in death rates. Figure 4 shows changes in mortality rates by age, separately for men and women. There has been a dramatic increase in prime age mortality in Russia. The death rate for men aged 35-44 rose by 74 percent between 1989 and 1994. Similar increases were seen throughout the other working ages. The pattern for women is similar, but the magnitudes are smaller - mortality for 35-44 year old women rose by 59 percent over the period.

The Russian elderly of the 1990s had very difficult lives. Born in a period spanning civil war and revolution (1917-1921), the famines and purges of the 1930s, and the hardships of World War II, it is possible that these catastrophic events impacted the future mortality of these generations. Indeed, a substantial public health literature focuses on the impact of early life events on late life mortality - either in utero (Barker, 1992) or in childhood (Kermack et al., 2001). But the increase in mortality in the 1990 s does not seem related to this factor. Mortality among men aged 65-74 rose by only 25 percent between 1989 and 1994; for men aged 75-84, mortality rates increased by 14 percent. For elderly women, mortality rates rose by 18 and 15 percent, respectively, in the 65-74 and 75-84 age groups. Indeed, the age group with the largest increase in mortality was born in about 1950, after World War II and the worst of the hardships of the Stalin era.

Figure 5 shows data on cause of death, again differentially for men and women. Each bar in the chart is the share of total increase in mortality accounted for by that cause between 1989 and 1994. For example, the first bar shows that 42 percent of the increase in male mortality was the result of greater mortality from cardiovascular disease; within this category, 21 percent of the 
total increase in male mortality ( $1 / 2$ of the cardiovascular disease total) was due to the increase in deaths due to ischaemic heart disease. Cardiovascular disease is the leading cause of death in Russia, as in the United States, so the importance of this change is not surprising. Still, the magnitude of the increase in such a short period of time is unusual. We typically think of cardiovascular disease as a long-term process responding to life events building up over many years or decades; the Russian data suggest otherwise. Given the importance of cardiovascular disease in accounting for the mortality crisis, we examine this factor extensively in our empirical work.

Second in importance is external causes of death. The most important items in this category are accidental alcohol poisoning, unspecified violent deaths, homicide and suicide. A well-hidden secret of the Soviet Union was the extremely high death rate due to external causes. In 1989, for example, the standardized death rate due to external causes among men in Russia was over three times the European Union average (200.3 deaths per 100,000 population versus 62.9 deaths per 100,000), and for women the rate was twice as high.

Deaths due to external causes rose dramatically in Russia in the early 1990s, virtually doubling for both men and women. These changes account for one-fifth (women) to one-third (men) of the total increase in deaths between 1989 and 1994. Both suicide and homicide are important across the region; by the mid-1990s Lithuania had achieved the dubious distinction of having the highest male suicide rate in the world. We return to this cause, especially as it relates to alcohol, at a later point.

While many causes of death have increased, others fell. In all countries of Eastern Europe and the former Soviet Union, infant and child mortality rates declined throughout the 1990s; indeed, without these declines the fall in life expectancy in the 'mortality belt' would 
have been even more dramatic. Infants and the elderly are typically the most vulnerable groups in the population. In countries facing economic shocks, mortality often increases in these ages the most (Cutler et al. 2002). As in so many other ways, however, the countries of the former Soviet Union are different.

Official data do not differentiate deaths by socioeconomic status (nor do they in the United States), but other evidence suggests that mortality rates increased the most among lower socioeconomic groups. For example, Shkolnikov et al. (1998) and Plavinski et al. (2003) note that men with low levels of education were disproportionately affected by the increase in mortality. Data from the Russian Longitudinal Monitoring Survey (described below) support this observation. Over the period 1995 - 2001, the average annual mortality rate of people aged 3055 was 0.74 percent. The mortality rate ranged from 1.86 percent of those with primary education to 0.23 percent of those with higher education, reflecting a strong educational gradient in mortality (Table 1).

\section{Sources of Data}

In the next sections, we assess different explanations for these patterns in mortality. We use two sources of data. The first is national data from the 23 countries of the former Soviet Union and Eastern Europe. The mortality data are from the WHO Mortality database and national statistical yearbooks. ${ }^{5}$ We report regression results for mortality among prime-age men (ages 25-64), since this is the group where the mortality crisis is most acute. We have also examined mortality rates for women of the same ages. The results are similar so we do not report them.

\footnotetext{
${ }^{5}$ See www.euro.who.int/hfadb. We use the January 2004 data.
} 
As with any aggregate regression, it is difficult, if not impossible, to control for all the other causes affecting mortality rates. This is particularly true in a setting like that of the former Soviet Union, where economic and social changes were large and data quality is often poor. To isolate the theories we consider more concretely, we consider cause-specific mortality in addition to total mortality. We group mortality into three broad causes: cardiovascular disease, external causes of death (homicide, suicide, and accidental death), and all other.

Economic and social variables from the same countries are from the WHO Health for All Database (2004), the World Bank (2003), the EBRD Transition Report (2003) and the TransMONEE database (2003). We discuss specific data series as appropriate below.

The second source of data is panel data from the Russian Longitudinal Monitoring Survey (RLMS). The RLMS is a nationally representative panel survey from $1994-2002 .{ }^{6}$ The sample comprises roughly 4,000 households and 11,000 individuals in each round. The RLMS contains extensive information on income, health status, employment, and demographic characteristics of individuals and families, as well as on individual behavior such as smoking and drinking.

For families where there is at least one member surviving, the survey asks if anyone died during the time period. We are thus able to identify deaths among the vast majority of multipleperson households (about 85 percent of the population is in multiple-person households). Our analysis of mortality in subsequent sections in based on these multiple-person households. ${ }^{7}$

${ }^{6}$ There is an earlier panel component from 1992 to 1994, but we do not use this because of the shortness of the panel and concern about data quality in that period. A detailed description of the sampling design and implementation of the RLMS is available at the RLMS website at http://www.cpc.unc.edu/rlms.

${ }^{7}$ We stack each round of the survey so that each regression uses all rounds of the survey and includes multiple observations on individuals. Standard errors are clustered by individual to correct for these multiple observations. 
Trends in mortality in the RLMS match trends from the aggregate data, although the level of mortality in the RLMS is $10-20$ percent lower than the national data.

In our longitudinal data, we control for a number of individual characteristics: age, education, income, ${ }^{8}$ year of survey, and region of the country. We also control for past medical events such as whether the person ever had a heart attack, was diabetic, or had a stroke.

\section{Suspect 1: The Acute Medical Care System}

We start with the most obvious suspect: perhaps the economic changes substantially disrupted the medical care system in a way that made medical treatment less effective. ${ }^{9}$ One of the Soviet Union's most remarkable achievements was the development of a universal health care system that extended across the country and provided health care even in the remotest areas of the northern and eastern territories. The system provided the population with a wide range of medical services and was particularly successful in reducing deaths due to infectious diseases and deaths in infancy. The only medical expenditures paid for out-of-pocket were those for (subsidized) prescription drugs and for small nominal payments made to hospital staff to ensure

${ }^{8}$ The income control perhaps warrants some comment. In the cross-country data, we do not control for GDP, since we are interested in the total effect of the variables we examine on mortality, not the partial effect controlling for economic conditions. One could make the same argument about income in the micro data. We include the income control, however, to pick up the person's relative position in society. As noted above, relative position is strongly indicative of mortality, for reasons that may go beyond the specific theories we consider. In practice, our results are relatively similar if we include or omit the control for income. For example, the alcohol consumption measure is statistically significant at less than the 5 percent level with nearly identical coefficients whether or not the income control is included in the regression.

${ }^{9}$ The medical care explanation has been suggested by Ellman (1994). 
better care. Significant payments to doctors (on the order of one- to two-months' average wage) were reported but were relatively uncommon. ${ }^{10}$

An obvious candidate to explain the upsurge in mortality in the former Soviet Union is thus a collapse of the health care system during the transition, resulting from the disintegration of the USSR and the tremendous budgetary pressures of the early 1990s that led to drastic cutbacks in health care financing in many countries and a vast increase in out-of-pocket expenditures for patients. Indeed, the health system seems to have deteriorated since the collapse of the Soviet Union. For example, there are reports that many hospitals and clinics in the former Soviet Union have opened fee-paying services to compensate for funding shortfalls. Data from the Russian Longitudinal Monitoring Survey indicate a dramatic increase in the number of patients paying for care in Russia and in the price of that care: in 1992 only 6.2 percent of individuals hospitalized in the month prior to the survey reported that they paid money for medical care or treatment while in the hospital; of those that paid, the median payment amounted to 34 percent of the median monthly per capita income. By 1998, 45 percent of respondents indicated that they had paid for medical care while in the hospital, and the payment exceeded two-thirds of the median monthly per capita income (Table 2). Anecdotal evidence indicates that, while modern drugs are prescribed for conditions such as cardiovascular disease, many patients cannot afford to purchase

\footnotetext{
${ }^{10}$ That is not to say that the system worked entirely well. The fundamental nature of central planning hampered the effectiveness of the health care system in many areas. The development of the health care system reflected the overall growth strategy of the country, emphasizing quantity of care - growth in indicators such as doctors and hospital beds per capita - rather than quality of care; central planners also set quantitative targets for the number of beds occupied and the number of procedures performed in hospitals (Twigg 1998). Further, there were waits for medical care, as for everything else in the Soviet Union. Knaus (1981) and Ryan (1989) describe the Soviet health care system in the 1970s and 1980s.
} 
them (Reiss et al. 1996). Funding difficulties may also have led to a decrease in the capacity and effectiveness of the health care system itself.

Medical care might affect mortality through several channels. Some medical care is preventive: anti-hypertension medication reduces the probability of a stroke or heart attack, for example. Other care is curative, for example high-tech treatment of people who have had an adverse event. We consider the acute care setting first, and then return to preventive care.

To assess the importance of changes in acute care in explaining the mortality crisis, one would ideally like to identify whether the increase in death rates was due to an increase in cases (e.g., an increase in the number of heart attacks, strokes, etc.), or to an increase in the fatality rate; the latter would suggest a particularly large role for declining health care services in the mortality crisis.

Although data are limited, evidence suggests that the fatality rate changed little during the 1990s. For example, an extensive study of stroke incidence and mortality in Novosibirsk (located in western Siberia) and northern Sweden between 1987 and 1994 found that while the case fatality rate was significantly higher in Novosibirsk (28-43 percent) than in Sweden (12-21 percent), case fatality rates remained unchanged over the period in Novosibirsk; the substantial increase in stroke mortality in Novosibirsk was due to an increase in attacks rather than to higher fatality rates (Stegmayr et al. 2000). Indeed, medical care for some types of illnesses apparently improved in Russia in the 1990s: the recent decline in childhood leukemia deaths, for example, is attributed to improvements in care (Shkolnikov et al. 1999).

To examine this hypothesis further, we employ data from Russia and the other countries of the former Soviet Union and relate changes in prime-age male mortality to the change in the maternal mortality rate (death during childbirth). Since maternal mortality is almost entirely 
preventable through medical intervention, the change in the maternal mortality rate is a good measure of the collapse of the medical care system (CITE). The maternal mortality rate did not change appreciably in Russia over the 1990s, rising from 49.0 deaths per 100,000 live births in 1989 to 53.3 deaths in 1995 , then falling to 39.7 deaths by $2000 .{ }^{11}$ This suggests that the capacity of the basic health care system remained essentially unchanged.

Using the maternal mortality rate as a proxy for the state of the health care system, the first column of Table 3 reports the relation between log changes in prime age male mortality and log changes in maternal mortality between 1989 and 2000. Our sample consists of the 22 countries of the former Soviet bloc for which data are reliable. There is little relation between maternal mortality and male mortality. Indeed, adult male mortality actually fell in countries where maternal mortality rose, though not statistically significantly.

We considered other measures of the medical care system as well, focusing more directly on the availability of medical care resources. The second column relates the change in male mortality to the change in public and private medical spending. Medical spending will change with both demand and supply, but our hope is that the massive changes in the structure of society in most former Soviet bloc countries make the supply changes more important over this time period. ${ }^{12}$ The results are similar; more spending does not lower mortality. Indeed the coefficient on public health expenditures is positively related to the male prime-age death rate, indicating that reverse causality may be an issue. In any case, there is little evidence to support the

\footnotetext{
${ }^{11}$ Note that the maternal mortality in rate is high compared with that of the U.S., where the maternal mortality rate in 2000 was 9.8 per 100,000 live births.

${ }^{12}$ We have also experimented with direct quantity measures, including the number of hospital beds per capita and the number of doctors per capita, with similar results.
} 
hypothesis that a breakdown in the acute health care system is a primary cause of the mortality crisis.

The situation with preventive medications is more difficult to assess. The Russian Longitudinal Monitoring Survey indicates whether the person takes any medication, but not the type of medication. Still, use of any medication did not decline in Russia. In both 1993 and 2000 , about 38 percent of Russian adults reported taking any medication. As noted below, this is consistent with evidence that traditional risk factors for cardiovascular disease did not change.

\section{Suspect 2: Traditional Risk Factors for Cardiovascular Disease}

The finding that the case fatality rate for cardiovascular disease did not increase indicates that there was an increase in the incidence of serious cardiovascular disease. One thus moves naturally to risk factors for cardiovascular illness. Five traditional risk factors for cardiovascular disease have been identified in the (western) literature: hypertension or high blood pressure, high cholesterol, diabetes, obesity, and smoking.

\section{Obesity}

The RLMS collects data on BMI, which we examine over the time period. ${ }^{13}$ Figure 6 shows trends in the share of the population who are overweight or obese in Russia over the 1993 - 2000 period for prime-age adults. ${ }^{14}$ From 1993 to 2000, obesity increased slightly for both men

${ }^{13}$ In addition to its direct importance, obesity is related to high blood pressure, high cholesterol, and diabetes.

${ }^{14}$ The categories in Figure 6 are based on the following WHO definitions: overweight if Body Mass Index (weight in kilograms divided by height in meters squared) is greater than 25 and less than 29.9; obese if BMI is 30 or higher. Data from the Russian Longitudinal Mortality Survey suggest that mortality begins to increase after BMI reaches 31 for men (see Table 4). 
and women, apparently due to a shift from the 'overweight' category into obesity. ${ }^{15}$ At the same time, the RLMS also indicates little change in the share of people who are underweight over the period, suggesting that diminished ability to purchase the calories required for adequate nutrition is not the explanation for the mortality crisis. ${ }^{16}$

The RLMS data allow one to estimate the relation between weight and mortality in Russia. The first column of Table 4 reports odds ratios for death among men in the RLMS data. ${ }^{17,18}$ There is a U-shaped relation between BMI and mortality risk, as is found in western countries as well. But the very slight change in obesity predicts only minor changes in mortality risk: the BMI change over the 1990s predicts an increase in mortality rates of only .02 percent, suggesting that obesity can be ruled out as a primary cause of the mortality crisis.

\section{Tobacco}

\footnotetext{
${ }^{15}$ Note that the level of obesity among Russian men is much lower than that in the United States: in 2000, 12 percent of Russian men age 25-64 were obese, compared with 25 percent of U.S. men in 2001 (Statistical Abstract of the United States, 2003). For women, 28.5 percent of Russian women were obese compared with 24.7 percent of U.S. women.

${ }^{16}$ Other studies have corroborated the finding that overall nutritional status in Russia is remarkably resilient to the extreme fluctuations in household income that families have experienced in the last decade (Dore, Adair and Popkin 2003; Thomas and Stillman 2004).

${ }^{17}$ The Appendix reports similar regressions for women. The findings are qualitatively and quantitatively similar.

${ }^{18}$ The interpretation of odds ratios is as follows: for a dummy variable such as "poor health" in Table 4, an odds ratio of 1.91 indicates that the odds of dying are 91 percent greater when the individual is in poor health than if not. For continuous variables, such as the odds ratio of 1.06 on age, the odds of dying increase by 6 percent for each yearly increase in age.
} 
Smoking is associated with higher rates of cardiovascular disease, along with many cancers. ${ }^{19}$ Russians men smoke much more than European men - the ratio is about 2 to 1. Russian women smoke less than their European counterparts, despite the higher rate of circulatory disease deaths. However, while high levels of smoking among men may partly explain the high level of cardiovascular mortality in Russia, changes in smoking rates seem unlikely to explain the sharp increase in cardiovascular mortality rates in the early 1990s. Use of tobacco products did not increase greatly in Russia over the 1990s. ${ }^{20}$ As Figure 7 shows, the share of adult males who report smoking cigarettes every day was flat at about 60 percent, and the share of women who smoke increased only moderately. ${ }^{21}$ We thus attach little importance to the smoking explanation.

\section{Hypertension, High Cholesterol, and Diabetes}

Data on other cardiovascular disease risk factors in countries of the former Soviet Union are difficult to obtain. Even in western countries, precise data on the prevalence of elevated risk

${ }^{19}$ Data from the Russian Longitudinal Mortality Survey, reported in Tables 4 and Appendix Table 1, confirm this finding: smoking increases the odds of dying by 60 percent for men and by nearly 3 times for women compared with non-smokers. A study of death certificates in Udmurtia (in the Urals) also confirmed that higher rates of smoking significantly increase the odds of dying from cardiovascular disease (Shkolnikov et al. 2001b).

${ }^{20}$ Smoking-related deaths almost certainly evolve over the long periods of time; the western literature suggests a 20 to 25 year lag between smoking trends and mortality (???). But lung cancer death rates in Russia have fallen sharply since the early 1990s, suggesting the cardiovascular disease mortality increase is not a result of a long-term response to smoking trends (Shkolnikov et al. 1999).

${ }^{21}$ The Novosibirsk study reached similar conclusions. Smoking rates among Novosibirsk men are far higher than those of Swedish men ( 56 percent versus 21 percent daily smokers, respectively), but this rate remained stable over time. Among women, the smoking rate in Novosibirsk doubled, from 3 percent to 6 percent, but remained much lower than the Swedish level of 28 percent (Stegmayr et al. 2000). 
are sparse, since most people with moderately elevated risk are asymptomatic, and thus may not make their way into the medical system. Still, the evidence that we have suggests that these traditional risk factors did not change materially, and indeed that they are no higher in Russia and the Baltics than in western populations. For example, the Novosibirsk stroke study found not only that many stroke risk factors were lower in the Novosibirsk population than in the Swedish population, but that these risk factors remained stable or even improved in the Novosibirsk population over the period (Stegmayr et al. 2000). ${ }^{22}$ Epidemiological studies of cardiovascular risk factors in the Baltic countries also find few differences in traditional risk factors between these and western populations, as well as mildly favorable trends in these risk factors throughout the 1990s (Kristenson et al. 1997; Volozh et al. 2002; Domarkiené 1993).

\section{Summary}

The surprising finding from these data is that traditional risk factors explain relatively little of the increase in mortality in Russia. This leads us, as it has others, to consider nontraditional risk factors for mortality.

\section{Suspect 3: Alcohol}

The risk factor that has drawn the most attention in possibly explaining Russia's mortality crisis is alcohol. Alcohol consumption can affect mortality in many ways. Alcohol is a direct

${ }^{22}$ For example, total cholesterol levels were lower in the Novosibirsk population than in Sweden, and while these levels declined in both populations over the period, the decline in Novosibirsk exceeded that in Sweden. There is a higher prevalence of hypertension among the Russian population than the Swedish population, but again this prevalence decreased in Novosibirsk significantly from 1987 through 1994 (while stroke attack incidence in Novosibirsk increased by more than 50 percent over these years). 
cause of many accidental deaths. In addition, some recent evidence suggests that heavy alcohol consumption - especially binge drinking - could have lead to increased cardiovascular disease mortality.

Alcohol consumption is slightly lower in Russia than in Europe, ${ }^{23}$ but the composition of alcohol consumed differs markedly. Compared to their European counterparts, Russians consume a great deal more alcohol in the form of spirits rather than as beer or wine (Figure 8). In addition, alcohol consumption in Russia is much more likely to be 'binge drinking' than in Europe - 120 grams or more of hard alcohol per occasion. ${ }^{24}$ While moderate alcohol may be good for health, binge drinking could well be harmful.

Figure 9 shows the trend in annual consumption of alcohol (in liters of pure alcohol per year) from two sources: the official data from the WHO, and tabulations from the RLMS. ${ }^{25}$ The WHO data have the advantage of being present for all countries, but they have a potentially major drawback in being based on official alcohol sales. Many former Soviet countries experienced a flood of imports in the early 1990s, and these imports are believed to be omitted from the official measure of alcohol consumption. ${ }^{26}$ Alcohol consumption in the RLMS may

\footnotetext{
${ }^{23}$ For example, according to the WHO data, per capita consumption of pure alcohol in Russia was 10.8 liters per capita, compared with 11.1 liters per capita in the European Union in 2000 .

${ }^{24}$ This definition is based on the epidemiological literature (Malyutina et al. 2001; Malyutina et al. 2002). We also defined a second binge drinking measure based on 160 or more grams of alcohol per day; the results were nearly identical to those reported here and are omitted for brevity.

${ }^{25}$ The RLMS asks individuals whether they drank in the last 30 days, and if so, how many grams of various types of alcohol they usually consumed in a day. Total alcohol consumption is obtained by converting grams of beer, wine, vodka etc. into grams of pure alcohol based on the alcohol content of each.

${ }^{26}$ Russia's official measure of alcohol consumption does include estimates of unrecorded consumption. In addition, alcohol consumption data on Kazakhstan appear to be substantially in
} 
also be underestimated if individuals fail to report their alcohol consumption completely. For comparison purposes, the graph also shows the prime age male death rate.

Both surveys show a substantial increase in alcohol consumption in the early 1990 s - on the order of 25 - 30 percent between 1992 and 1994. The increase in alcohol consumption in the early 1990s is consistent with a substantial reduction in price: the relative price of alcohol fell by 58 percent between December 1990 and December 1994. Using the WHO data, the change in alcohol consumption and the price of alcohol between 1990 and 1994 implies a price elasticity of demand for alcohol of -.36 , which seems plausible. Increased alcohol consumption may also be related to the increased political and economic uncertainty in Russia in the early 1990s as the transition to a market economy began in earnest. Both surveys also show a reduction in alcohol consumption between 1994 and 1996; this corresponds to a relative increase in alcohol prices.

The RLMS and WHO data show a different trend after 1996, with alcohol consumption decreasing substantially in the RLMS until 1998 and then increasing thereafter. The WHO data show a smooth increase over most of the period. Over the entire 1992 - 2000 time period, alcohol consumption increased in Russia by between 27 percent (using the RLMS data) and 63 percent (using the WHO data).

The RLMS data in particular track closely the changes in the male standardized death rate over time: alcohol consumption increased, and so did mortality. The Appendix shows alcohol consumption for other Soviet bloc countries. Alcohol consumption increased significantly in some of the 'mortality belt' countries in the early 1990s - in particular, in Lithuania, Moldova and Russia - while it changed little or declined in the countries of Central and Southern Europe. This too is suggestive of an alcohol-based explanation for the mortality crisis.

error, so we omit that country from this part of the analysis. 


\section{Alcohol and Violent Deaths}

One clear case where alcohol may affect mortality is through violent death. Accidental alcohol poisoning represents 7 percent of the increase in male mortality between 1989 and 1994, and 6 percent of the increase in female mortality. In addition, alcohol may play some role in other violent deaths as well, either by instigating murder or suicide, or as a disguised cause of them.

The cross-country data help shed light on the importance of alcohol in death from external causes. The first column of Table 5 shows the relation between changes in alcohol consumption and changes in death from external causes. The coefficient on alcohol consumption is positive, but not statistically significant. Still, the coefficient is large; the 45 percent increase in alcohol consumption in Russia between 1989 and 2000 (using the WHO data) is predicted to account for 34 percent of the increase in all external causes of death. ${ }^{27}$

For 2000 - 2002 the RLMS also provides information on causes of death; we exploit these data to investigate the relation between alcohol consumption and accidental deaths. Because the sample size and number of deaths over this period is limited, we restrict the analysis to men only. The first three columns of Table 6 report logistic models for the probability of accidental death in the RLMS. Alcohol consumption is positively and significantly related to accidental deaths, as shown in column (1). As column (2) shows, this is particularly related to binge drinking. Men who binge drink are nearly four times more likely to die of accidental deaths than are people who do not drink. Comparing the coefficients from the RLMS regressions

\footnotetext{
${ }^{27}$ This figure is calculated by multiplying the coefficient on alcohol consumption by the log change in alcohol consumption in Russia over this period $(.432 \times .450=.194)$, and dividing by the log change in external cause mortality in Russia $(.194 / .565=.34)$. The contributions of other factors to the increase in death rates in Russia based on the cross-country regressions, discussed below, are calculated similarly.
} 
with those of the cross-country regressions, the former indicate that the increase in alcohol consumption in Russia between 1989 and 2000 (as measured by the WHO data) accounts for approximately 8 percent of the increase in accidental deaths among prime-age men during this period; the latter indicates that alcohol consumption accounts for 34 percent of the increase in accidental deaths. ${ }^{28}$

\section{Alcohol and Cardiovascular Disease}

While studies show that moderate alcohol consumption has favorable effects on health, some evidence suggests that binge drinking may be harmful to cardiovascular health. McKee and Britton (1998) review the epidemiological literature on the relationship between alcohol consumption and cardiovascular mortality and conclude that there is a physiological mechanism for a relationship between alcohol consumption, particularly binge drinking, and increased risk of death due to cardiovascular disease ${ }^{29}$ Arrhythmias and heart attacks seem particularly related to binge drinking. A small case-control study of adult male deaths in Udmurtia confirmed that cardiovascular deaths are strongly associated with heavy drinking (Shkolnikov et al. 2001b). Further, the number of cardiovascular deaths among men in Russia in 1993 - 1995 was significantly higher on Saturdays, Sundays, and Mondays than on other days of the week, which the authors argue is likely due to increased alcohol consumption on weekends (Chenet et al. 1998).

${ }^{28}$ Because the coefficients on the logistic regressions are not directly comparable with those of the cross-country regressions, we re-estimate the RLMS regressions as linear probability models in order to calculate the contribution of each coefficient to the probability of dying.

${ }^{29}$ This mechanism operates through the increased risk of thrombosis and hemorrhagic stroke which result from excessive alcohol consumption, as well as through the reduced protective actions of HDL ("good") cholesterol which occur with heavy drinking. 
Other researchers, however, have disputed the claim that Russia's high cardiovascular mortality is due to excessive alcohol consumption. Bobak and Marmot (1999) point out that the similar relative increase in mortality among men and women in Russia is inconsistent with an alcohol-based explanation, since Russian women drink far less than Russian men. A similar conclusion comes from looking across regions of the former Soviet Union. Among the former Soviet bloc countries are Uzbekistan and Turkmenistan, both Muslim countries where reported alcohol consumption is low, particularly consumption of spirits: per capita consumption of spirits was .02 and .01 liters of pure alcohol, respectively, in Turkmenistan and Uzbekistan in 2000, and total alcohol consumption was one-tenth the Russian level. Still, cardiovascular disease mortality in these countries rose by 23 and 25 percent respectively between 1989 and 1994.

Bobak and Marmot also show that the alcohol effect would have to be much greater to explain the increase in cardiovascular disease mortality: not only would the prevalence of heavy drinking have had to have increased from 20 to 50 percent of the population, but the harmful effects of alcohol consumption (i.e. the relative risk) would have had to have more than doubled as well, which seems implausible.

In addition, a study of men aged 25-64 living in Novosibirsk who were followed between 1985 and 1994 found a higher risk of cardiovascular disease death in a small group of frequent heavy drinkers, but not among binge drinkers (Malyutina et al. 2002). Since frequent heavy drinkers - defined as drinking at least 120 gram of ethanol per occasion at least three times per week - make up only 5 percent of all drinkers and 4 percent of all Russian men, this study concluded that alcohol is unlikely to provide the sole explanation for the increase in mortality in Russia; the authors estimate that even if the rates of frequent heavy drinking are five times higher 
than estimated based on surveys, it is still the case that alcohol consumption can explain at most 8 percent of deaths from cardiovascular disease. Finally, the authors of a study of cholesterol levels in St. Petersburg argue that the substantial decline in HDL ("good") cholesterol levels observed among the population in the 1990s contradicts an alcohol-based explanation for the Russian mortality, since regular consumption of alcohol raises the level of HDL cholesterol (Plavinski et al. 1999).

Both our cross-country and longitudinal data provide evidence on the link between alcohol consumption and cardiovascular disease mortality. The second column of Table 5 shows the impact of alcohol consumption on cardiovascular deaths using the cross-country sample. The coefficient is positive, but not statistically significant $(\mathrm{p}$ value $=.122)$. The magnitude is relatively large, however. An increase in alcohol consumption like that seen in Russia would increase cardiovascular disease mortality by 10 percent.

The micro data from the RLMS (Table 6) suggest no impact of alcohol consumption on cardiovascular mortality, even from binge drinking. The coefficient on alcohol consumption suggests a slight protective effect of drinking for cardiovascular health, but is not statistically significant.

\section{Total Effect}

The total effect of alcohol consumption on mortality in the international data is shown in Table 3. In the cross-country data, alcohol consumption has a positive, statistically significant effect on total mortality. The coefficient is large: it implies that the increase in alcohol consumption in Russia explains about 25 percent of the increase in mortality in Russia between 1989 and 2000. 
The RLMS data also suggests an effect of alcohol consumption on mortality. The second column of Table 4 adds a measure of alcohol consumption to the regression in the first column. Alcohol is positively and statistically significantly associated with mortality. ${ }^{30}$ Using the coefficient on alcohol consumption from a linear probability estimate of this model, an increase in alcohol of the magnitude seen in Russia over 1989 - 2000 is predicted to increase mortality by 12.6 percent, or 22.3 percent of the total increase in mortality. The estimates from the micro and macro data are thus consistent: ${ }^{31}$ in total, about one-quarter of the increase in Russia stems from the increase in alcohol consumption over the 1990s.

\section{Suspect 4: The Composition of the Diet}

While weight has fluctuated little in Russia over the course of the transition, Russian households have responded to the income shocks by shifting the composition of their diets towards cheaper foods. This dietary shift may be one of the causes of the increase (and subsequent decrease) in cardiovascular mortality among the population.

The Russian diet has long been low in fruit and vegetable content, due to the difficulty of growing such foods in the Russian climate and the priority placed by the country's leadership, beginning with Khrushchev, on increasing the consumption of meat and dairy products. As a result, research has shown that severe antioxidant deficiencies exist in some Russian

${ }^{30}$ In other results (not shown), we have divided alcohol into different types. Vodka and samogon (homemade alcohol) seem to be most harmful to health, while wine consumption appears to be protective.

${ }^{31}$ In the micro data, there does not seem to be a particular harm from binge drinking, although the measurement of binge drinking may be somewhat problematic. 
populations. $^{32}$ Although fruits and vegetables became much more widely available in Russia as market reforms were implemented in the early 1990s, consumption of these goods remained extremely low in comparison with western countries and declined sharply during the first half of the decade: average per capita consumption of vegetables in Russia fell from 85 kilograms per year in 1990 (75 percent of the US level) to 71 kilograms in 1994 (Figure 10). Consumption increased as incomes stabilized after 1994, then fell sharply again following the 1998 financial crisis. As is evident from Figure 10, the changes in vegetable consumption closely track the erratic changes in male life expectancy in Russia.

Meat consumption is also much lower in Russia than in the west, and was declining over the time period, from 60 percent of the US level in 1990 to 40 percent in 1997. Meat may have a positive or negative effect on health, especially the fatty meats commonly consumed in Russia.

While research on the impact of diet on health is not complete, some research suggests that the composition of the diet may be an important risk factor for cardiovascular disease. Ginter $(1995,1997)$ argues that antioxidant deficiency, stemming from the low level of fruit and vegetable consumption in the former Soviet Union, may play an important role in the development of cardiovascular disease, in particular that such a deficiency may interact with other conditions in society (such as pollution, alcohol consumption, and smoking) to promote cardiovascular disease development. At least two recent studies suggest that these dietary imbalances may translate into heightened risk for cardiovascular disease in the former Soviet population. A study of 50-year old Lithuanian and Swedish men conducted in 1993-1994

${ }^{32}$ For example a 1992 study found that 93 percent of men living in Karelia, Russia had severe vitamin $\mathrm{C}$ deficiency, as compared with 2 percent of Finnish men in a neighboring region (Matilainen et al. 1996). 
showed that plasma concentrations of antioxidant vitamins were lower in the Lithuanian men than Swedish men, and that the Lithuanian men had a strikingly reduced resistance of LDL ("bad") cholesterol to oxidation. The authors argue that antioxidant deficiency likely contributes to the much higher mortality rates from coronary heart disease among Lithuanian men compared with Swedish men (Kristenson et al. 1997). A separate study of St. Petersburg residents showed a dramatic increase in the number of men with dangerously low levels of HDL cholesterol in the 1990s: in 1986-1988 6 percent of St. Petersburg men age 40 to 49 had low levels of HDL cholesterol; by 1995-1997 36.4 percent of men in this age group had low levels of HDL cholesterol. The decline in HDL cholesterol levels was similar across all men in the 20 to 69 age group, and for women as well (Plavinski et al. 1999).

Dietary change may also be one of the few factors that can explain (in part) the widely divergent patterns of mortality across Eastern Europe and the former Soviet Union. Several studies attribute the dramatic decrease in cardiovascular mortality in Eastern Europe to the changes in diet that occurred following price liberalization (Bobak et al. 1997; Poledne and Škodová 2000; Witold et al. 1998). In many countries, the prices of meat and dairy products were heavily subsidized, and the availability of fruits and vegetables was limited. Price liberalization, the removal of subsidies, and an increase in food imports led to a dramatic reduction in the relative price of fruits and vegetables, and a significant increase in their consumption. Combined with the relative increase in the price of meat and dairy products, these 
changes led to a substantial improvement in the ratio of vegetable to animal fats consumed among these populations. ${ }^{33}$

We examine the importance of the dietary change hypothesis using the international data. The WHO Health for All database estimates average fruit and vegetable availability per person per year (in kilograms). For many countries in the former Soviet Union, these data are available only beginning in 1992, so the change for some countries is over the $1992-2000$ period. Both the levels and changes in fruit and vegetable consumption differ markedly across countries and over time: In Russia, for example, average fruit and vegetable consumption fell from 121 to 105 kilograms per capita between 1992 and 1994, then rose to 114 kilograms by 1998; in contrast, in Slovenia the average consumption rose from 117 to 188 kilograms per capita between 1992 and 1998.

The results are presented in the fourth column of Table 3. The coefficient on fruit and vegetable consumption is negative as expected, but is statistically significant at only the 16 percent level. Even taken at face value, however, the impact of changes in the composition of the diet is small. Fruit and vegetable consumption in Russia fell by less than 4 percent over the entire time period. The implied change in mortality is less than 3 percent of the change in overall prime-age male mortality between 1992 and 2000 .

As with alcohol consumption, we are interested in how fruit and vegetable consumption affects particular causes of death. Table 5 shows that increased fruit and vegetable consumption is statistically significantly negatively associated with cardiovascular disease mortality, as the

${ }^{33}$ For example, in the Czech Republic, the average per capita consumption of butter fell from $9.4 \mathrm{~kg}$ in 1989 to $5.4 \mathrm{~kg}$ in 1992 (Bobak et al. 1997), while consumption of fruit and vegetables increased from 68 to $87 \mathrm{~kg}$ between 1989 and 1997 (Poledne and Skodova 2000). In Poland, consumption of animal fat fell from 101 to 77 grams per day between 1989 and 1994, while consumption of vegetable fat increased from 28 to 40 grams per day (Sekula et al. 1997). 
theory suggests. Still, the coefficient implies that changes in fruit and vegetable consumption

explain only 2 percent of the increase in cardiovascular mortality among Russian men over this period.

While fruit and vegetable consumption cannot explain the increase in Russian mortality over the entire time period, it might well be a factor in the initial effect of transition. Over the 1992-94 period, the decline in fruit and vegetable consumption in Russia can explain 28 percent of the increase in cardiovascular disease mortality. And as noted above, the change in diet is a distinguishing factor between Russia and Eastern Europe. If fruit and vegetable consumption in Russia had mirrored that in Slovenia between 1992 and 2000, our regressions suggest that Russian mortality would have fallen by nearly 10 percent over the 1990s, narrowing the primeage male mortality gap with eastern Europe by nearly 50 percent. $^{34}$

Unfortunately, we cannot examine the dietary composition theory using the RLMS data. While the RLMS asks respondents to provide detailed information on the type and quantity of food consumed in the previous 24 hours, these data have not yet been released for public use. On the basis of the aggregate data, we conclude that changes in the composition of the diet cannot explain the absolute increases in mortality in Russia, but helps explain some of the divergence with other eastern European countries.

\section{Suspect 5: Material Deprivation}

${ }^{34}$ While dietary change may gradually affect health, the evidence described above for Eastern Europe suggests that the effects of decreased fat consumption and increased fruit and vegetable consumption may lead to a rapid decline in cardiovascular disease (Zatonski et al. 1998; Poledne and Skodova 2000). This is also consistent with the rapid decline in cardiovascular disease mortality in German-occupied Norway during World War II, coincident with the dramatic enforced decline in meat and dairy consumption in the country during those years (Zatonski et al. 1998). 
The transition from communism led to a significant devaluation of human capital. In Russia, for example, the wages of men with 30 or more years of work experience actually fell below the wages of new entrants to the work force (Brainerd 1998). Coupled with this is a very weak government safety net - weaker in Russia than in many other mortality belt countries. Russia, for example, lacks a national means-tested benefit program for families living below the poverty line. One hypothesis for increased mortality is thus that severe economic hardship increased, and this led to increased mortality (Lynch et al., 2000).

We noted above that the share of the Russian population that is underweight did not change over the time period, but this is only one measure of material deprivation. It may be, for example, that people kept up caloric intake but cut back on energy in winter or did more manual labor at home. Our RLMS data allow us to examine the effect of additional aspects of material deprivation on mortality. The fifth column of Table 4 includes various measures of hardship in the mortality regressions - whether the family is in poverty or extreme poverty $;{ }^{35}$ whether the family received subsidies for fuel; whether the family had to sell goods to obtain money for food; and the share of total household expenditures on food. All of these variables are statistically insignificant in these regressions and many of the coefficients are small in magnitude. These results thus suggest that material deprivation is unlikely to explain the upsurge in mortality in Russia and the other former Soviet republics.

\section{Suspect 6: The Stress of Transition}

${ }^{35}$ The poverty measure is based on the official Russian poverty measure, which in turn uses a representative subsistence food basket and a food to total expenditure multiplier to determine the poverty line. A household is in extreme poverty if its income is less than half of the poverty line. 
Before 1989, Russians lived in a country that provided complete economic security: unemployment was virtually unknown, pensions were guaranteed and provided an adequate standard of living, and macroeconomic instability had never affected the average citizen. The economic reforms implemented in 1992 created an upheaval in the country that, while beneficial in many ways, changed the life course of virtually every citizen in the country. For the first time, the average Russian confronted a completely unpredictable future.

Unpredictability is an example of a psychosocial factor that may influence health. The link between stress and health is the most explored factor. 'Stress' arises when an individual perceives a discrepancy between the demands of a situation and the physical or psychological capacity to respond to those demands (Shapiro 1995). A high level of stress is related to the development of cardiovascular disease - even independent of its effect on dietary and lifestyle factors -- although the physiological mechanisms for the link between stress and cardiovascular disease remain unclear (Labarthe 1998; Sapolsky, 1998).

Other psychosocial factors may affect health as well. Greater despair or hopelessness among middle-aged men is associated with higher risk of heart disease and heart attack, as well as earlier onset of artery disease, even controlling for risk factors such as alcohol consumption and smoking (Everson et al. 1997). ${ }^{36}$ People who have more social support are similarly likely to have improved outcomes over those with less support (Berkman et al., 1992).

A number of indicators suggest increased psychosocial problems in the former Soviet Union, especially Russia. As noted above, suicide rates rose dramatically in the early years of transition, particularly among middle-aged men. By 1994, in fact, the suicide rate for Russian

${ }^{36}$ Increased stress may also induce behavior with adverse health consequences, such as reckless driving and increased alcohol consumption. These effects are captured in our previous analysis. 
men aged 50-54 was over six times higher than that in the U.S. (139 and 22.5 deaths per 100,000 population, respectively). In contrast, suicide rates remained constant or fell in Eastern Europe; in Hungary, for example - a country with one of the highest suicide rates in the region historically - the suicide rate for men aged 25-64 fell from 84.4 per 100,000 population in 1989 to 65.0 in 1995.

Russians also tend to have more negative expectations about the future than do their East European counterparts. The Central and East European Barometer (CEEB) program has conducted surveys of Russia and Eastern European countries beginning in the early 1990s and ending in 1996. Among the questions asked is one about expectations of future financial circumstances: "Over the next twelve months, do you expect that the financial situation of your household will: (1) get a lot better; (2) get a little better; (3) stay the same; (4) get a little worse; (5) get a lot worse." The average in Russia is nearly 3.5, among the highest on the list and far more pessimistic than the more successful East European countries such as the Czech Republic and Slovenia (Figure 11).

Cross section data also suggest that expectations about the future may play a role in mortality increases. Figure 12 shows that prime-age people are the most pessimistic age group in Russia, even more so than the elderly.

To examine the role of psychosocial factors in explaining health in Russia, we relate mortality rates across countries to suicide rates. Figure 13 shows the relation between changes in suicide and overall mortality (less death from suicide), and Table 3 shows the regression. The male suicide rate is positively and significantly correlated with the change in the overall death rate. The coefficient is reasonably large; this proxy for stress explains nearly one-quarter of the 
increase in mortality in Russia over the time period. ${ }^{37}$ As Table 5 shows, suicide is significantly correlated with other external causes of death, ${ }^{38}$ but not cardiovascular disease mortality.

Understanding which factors lie behind this relation is more difficult, since we can only test some theories. As noted above, diminished expectations about the future is one possible mechanism. Figure 14 shows some tendency for countries with a worsening of expectations about the future to have worse outcomes, though this relationship is not statistically significant for all-cause mortality (Table 3). Poor expectations is a somewhat more significant predictor of death from external causes (Table 5; -value=.11).

The RLMS data show a similar relation. The RLMS asks people: "Do you think that in the next twelve months your family will live better than today, or worse?" Answers range from "much better (=1)" to "much worse (=5)." We define an indicator of positive expectations which is equal to one if the individual answered 1 or 2 ("will live somewhat better") to this question. The sixth column of Table 4 shows that the odds of dying are 30 percent lower for men who have positive expectations about the future (the coefficient is significant at the 11.3 percent level); for women the odds of dying are 50 percent lower (reported in the Appendix table). Note that this effect is found controlling for income; this is not a finding that the poor are more likely to die than the rich, rather that those with lower expectations are in worse health, even given their income.

${ }^{37}$ Suicide is a part of total mortality, but the impact here is substantially greater than just the direct effect. The direct effect is about 4.5 percent of the mortality increase for men and 1 percent for women, as shown in Figure 5.

${ }^{38}$ Note that the dependent variable in this regression is calculated as death rate due to external causes minus the death rate due to suicide, so that the relationship between suicide and external causes of death is not a mechanical one. 
While the data show clearly that expectations are important for health, the regressions are also clear that changes in outlook for the future cannot be the whole explanation for the increase in mortality in Russia. Figure 15 shows the trend in expectations in Russia using the CEEB data through 1996, and similar data from the RLMS from 1994 to 2002. There was surprisingly little change in future expectations in the early years of transition in Russia. Expectations improved slightly through 1993, and then returned to their prior level. Expectations got worse in the financial crisis of 1998, but after that, expectations improved substantially. This is at the same time that mortality rates in Russia were increasing; in particular, male life expectancy at birth fell from 61.3 years in 1998 to 58.5 years by 2002 . Thus, the time series of the change in expectations about the future does not match the time series of the change in mortality. ${ }^{39}$

Psychosocial distress may be related not to average expectations about the future, but to the fear of very bad outcomes. Uncertainty associated with the possibility of becoming very poor may create stress sufficient to result in harm to health. To test this hypothesis, we use data on the change in the minimum wage as a percentage of the average wage across countries (for the country-level regressions) and across Russia's regions (for the individual data). We choose the minimum wage as our measure of poor outcomes for several reasons. Besides its direct effect on wages, many countries use the minimum wage as a base for setting the level of other social benefits such as child care allowances and student stipends. And while other measures of government support such as the level of unemployment benefits or government spending on social benefits may be preferable, consistent measures of these variables across countries or across Russia's regions are not available.

${ }^{39}$ There might, of course, be a lagged effect of expectations on health, but our data are not refined enough to permit such an analysis. 
Minimum wages have changed dramatically in many transition countries over the 1990s. For example, the minimum wage in the Soviet Union was $30-35$ percent of the average wage in the late 1980s; it fell to less than 6 percent of the average wage in Russia by 2000. Moreover, throughout much of the 1990s the minimum wage in Russia was far below the 'subsistence minimum' calculated by the government for determining poverty rates. For example, in 1996 the minimum wage was 75,900 rubles per month, while the average subsistence minimum (which varies by region and demographic group) was approximately 375,000 rubles per month. In contrast, many of the East European countries maintained a relatively high minimum wage throughout the 1990s, for example exceeding 34 percent in Poland and 42 percent in Hungary in 2001.

Table 3 shows that the log change in the minimum wage as a share of the average wage is negatively and significantly related to the change in mortality for all causes. It is also strongly negatively related to the increase in cardiovascular disease deaths (Table 5). The coefficient on minimum wages in the 'all causes' regression indicates that the reduction in the minimum wage can explain 34 percent of the increase in deaths in Russia over the 1989 -2000 period.

The last column of Table 4 shows analogous regressions using the RLMS micro data. The minimum wage is statistically insignificant in the RLMS regressions for 'all causes', but, consistent with the cross-country evidence, is statistically significant at the 7.8 percent level for cardiovascular disease deaths and is insignificant for external cause deaths (Table 6). The coefficient on the minimum wage for cardiovascular disease deaths is large; in linear probability form, the change in the minimum wage can explain 98 percent of the increase in male cardiovascular disease deaths in Russia, or roughly 40 percent of the increase in all male deaths in the country. 
Recall that the minimum wage is not a proxy for poor individual circumstances. Direct measures of material deprivation such as poverty and having enough food do not predict mortality. Rather, mortality appears to be associated with the prospect of suffering a substantial reduction in income, and hence living standards.

Both our micro and macro data thus show clear impacts of psychosocial factors on mortality. Our estimate is that psychosocial factors as a whole explain about one-quarter of the increase in Russia over the 1990s. In looking at particular causes, the data are most consistent with the idea that the tattering of the social safety net combined with great economic dislocation have led to significant stress, and attendant poor outcomes. The exact mechanism linking these factors, however, remains to be explored.

\section{Conclusions}

Our analysis of mortality in Russia and other countries of the former Soviet Union leads us to highlight two significant causes of the mortality crisis. The first cause is increased alcohol consumption. Our results in the cross-country and micro data are fairly consistent; in each case, about a quarter of the increase in mortality in Russia is due to increased alcohol use. Much of this alcohol use is a reflection of the lower price of alcohol over time, though factors such as the loosening of the Gorbachev-era restrictions on alcohol availability almost certainly played a role as well. Increased stress from the transition to a market economy also seems to play a role in Russia's mortality crisis. The second factor is psychosocial stress, likely brought on by the substantial changes in the economic environment and a material reduction in the social safety net. We have a range of estimates of the impact of psychosocial distress on mortality, but a best guess is perhaps that it can explain one quarter of the increase in mortality. 
Other theories find little support in our data. We find no evidence that a reduction in the effectiveness of the medical care system is related to increased mortality. Nor do we find evidence that a change in the composition of the diet is related to increases in Russian mortality, though more favorable dietary changes in Eastern Europe seem to explain some of the good demographic news enjoyed by those countries.

The major remaining question is how to explain the approximately half of the mortality reduction that is unaccounted for by the factors we identify. It is, of course, possible that the factors we identify are the right ones, and that the uncertainty encompasses the full mortality change. Alternatively, there may be factors beyond what we have considered that are important in the Russian mortality crisis. Analysis of such factors will have to await the future. 


\section{References}

Anderson, Barbara A. and Brian D. Silver, "Issues of Data Quality in Assessing Mortality Trends and Levels in the New Independent States," in J.-L. Bobadilla, C. Costello and F. Mitchell, eds., Premature Death in the New Independent States (National Academy Press, Washington, D.C., 1997), 120-55.

Badurashvili, I., M. McKee, G. Tsuladze, F. Mesle, J. Vallin and V. Shkolnikov, "Where There Are No Data: What Has Happened to Life Expectancy in Georgia Since 1990?” 2001. Public Health. 115, pp. 394-400.

Barker, David J.P., Fetal and Infant Origins of Adult Disease, London: BMJ Books, 1992.

Berman LF, Leo-Summers L, and Horwitz RI, "Emotional Support and Survival After Myocardial Infarction: A Prospective, Population-Based Study of the Elderly," Annals of Internal Medicine, 1992, 117(12): 1003-1009.

Bobak, Martin, Zdenka Skodova, Zbvnek Pisa, Rudolf Poledne, Michael Marmot, "Political changes and trends in cardiovascular risk factors in the Czech Republic, 1985 - 1992," Journal of Epidemiology and Community Health 1997, 51: 272 - 277.

Bobak, Martin and Michael Marmot, "Alcohol and Mortality in Russia: Is It Different Than Elsewhere?” Annals of Epidemiology, Vol. 9, No. 6 (August 1999): 335 - 338.

Brainerd, Elizabeth, "Winners and Losers in Russia's Economic Transition," American Economic Review Vol. 88 no. 5 (December 1998), 1094 - 1116.

Chenet, Laurent; David Leon; Martin McKee; Serguei Vassin, "Deaths from Alcohol and Violence in Moscow: Socio-economic Determinants," European Journal of Population 14, 1998, 19-37.

Cornia, Giovanni Andrea and Renato Paniccià, "The Transition Mortality Crisis: Evidence, Interpretation and Policy Responses," in Cornia, Giovanni Andrea and Renato Paniccià, eds., The Mortality Crisis in Transitional Economies (Oxford, UK: Oxford University Press, 2000), 3-37.

Cutler, David M. et al., "Financial Crisis, Health Outcomes and Ageing: Mexico in the 1980s and 1990s," Journal of Public Economics, May 2002, 84(2): 279 - 303.

Domarkiené, Stanislava et al., "Trends in main cardiovascular risk factors among middle-aged Kaunas population between 1983 and 2002," Medicina (2003), Vol. 39, no. 12, 1193 1199.

Dore, Anna R., Linda S. Adair and Barry M. Popkin, "Low Income Russian Families Adopt Effective Behavioral Strategies to Maintain Dietary Stability in Times of Economic Crisis," Journal of Nutrition 2003, 133: 3469 - 75. 
Ellman, Michael, "The Increase in Death and Disease Under 'Katastroika", Cambridge Journal of Economics, August 1994, 18 (4): 329 - 355.

Everson, Susan A., George A. Kaplan, Debbie E. Goldberg, Riitta Salonen and Jukka T. Salonen, "Hopelessness and 4-Year Progression of Carotid Atherosclerosis: The Kuopio Ischemic Heart Disease Risk Factor Study," Arteriosclerosis, Thrombosis, and Vascular Biology 1997, 17: 1490 - 1495.

Field, Mark G. "The Health Crisis in the Former Soviet Union: A Report from the 'Post-War' Zone," Social Science and Medicine 41:11 (1995), 1469 - 1478.

Flanagan, Robert J. "Wage Structures in the Transition of the Czech Economy," International Monetary Fund Staff Papers, December 1995, 42(4), 836-54.

Ginter, Emil, "High Cardiovascular Mortality in Postcommunist Countries: Participation of Oxidative Stress?" International Journal of Vit Nutr Res 1996, 66: 183-189.

Ginter, Emil, “Cardiovascular Disease Prevention in Eastern Europe,” Nutrition, 1998, 14 (5): 452-457.

Kermack W, McKendrick A, McKinley P. Death rates in Great Britain and Sweden. Some general regularities and their significance. International Journal of Epidemiology 2001;30:678-683

Knaus, William A., Inside Russian Medicine (New York: Everest House, 1981).

Kristenson, Margareta; Zieden, Bo; Kucinskiene, Zita et al, "Antioxidant State and Mortality from Coronary Heart Disease in Lithuanian and Swedish Men: Concomitant Cross Sectional Study of Men Aged 50," British Medical Journal 1997, 314: 629-??.

Labarthe, Darwin R., Epidemiology and Prevention of Cardiovascular Diseases: A Global Challenge (Aspen: Gaithersburg, MD, 1998).

Leon, David A.; Laurent Chenet; Vladimir M. Shkolnikov et al, "Huge Variation in Russian Mortality Rates 1984-94: Artefact, Alcohol, or What?" The Lancet 1997, 350: 383-388.

Lynch, JW, Davey Smith, G, Kaplan GA and House, JS, "Income Inequality and Mortality: Importance to Health of Individual Income, Psychosocial Environment, or Material Conditions," British Medical Journal 2000, 320: 1200 - 1204.

Matilainen, T., E. Vartiainen, P. Puska, G. Alfthan, S. Pokusajeva, N. Moisejeva and M. Uhanov, "Plasma Ascorbic Acid Concentrations in the Republic of Karelia, Russia and in North Karelia, Finland," European Journal of Clinical Nutrition (1996), 50, 115-120. 
Malyutina, Sofia, Martin Bobak, Svetlana Kurilovitch, Eva Ryizova, Yuri Nikitin and Michael Marmot, "Alcohol Consumption and Binge Drinking in Novosibirsk, Russia, 1985-95," Addiction, vol. 96, no. 7 (July 2001), 987-995.

Malyutina, Sofia, Martin Bobak, Svetlana Kurilovitch, Valery Gafarov, Galina Simonova, Yuri Nikitin, and Michael Marmot, "Relation between heavy and binge drinking and all-cause and cardiovascular mortality in Novosibirsk, Russia: a prospective cohort study," The Lancet, Vol. 360 (Nov. 9, 2002), 1448 - 1454.

McKee, M. and Annie Britton, "The Positive Relationship Between Alcohol and Heart Disease in Eastern Europe: Potential Physiological Mechanisms," Journal of the Royal Society of Medicine, Vol. 91 (August 1998), pp. 402 - 407.

Plavinski, S.L.; Plavinskaya, S. I.; Richter, V. et al, “The Total and HDL-Cholesterol Levels in Populations of St. Petersburg (Russia) and Leipzig (Germany)," Nutr Metab Cardiovasc Dis 1999 9: 184-191.

Plavinski, S. L., Plavinskaya, S. I., and A. N. Klimov, "Social factors and increase in mortality in Russia in the 1990s: prospective cohort study," British Medical Journal 326 (June 2003), $1240-1242$.

Poledne, R. and Z. Škodová, “Changes in nutrition, cholesterol concentration, and cardiovascular disease mortality in the Czech population in the past decade," Nutrition 2000, 16: 785 786.

Puska, Pekka; Matilainen, Tiina; Jousilahti, Pekka et al, "Cardiovascular Risk Factors in the Republic of Karelia, Russia, and in North Karelia, Finland," International Journal of Epidemiology, 1993, 22 (6): 1048-1055.

Reiss, James Arthur, Nathan Every, and W. Douglas Weaver, "A comparison of the treatment of acute myocardial infarction between St. Petersburg, Russia and Seattle, Washington," International Journal of Cardiology 53 (1996), 29 - 36.

Ryan, Michael, Doctors and the State in the Soviet Union (London: Macmillan, 1989).

Rutkowski, Jan, "High Skills Pay Off: The Changing Wage Structure During Economic Transition in Poland," Economics of Transition, May 1996, 4(1): 89-111.

Sapolsky, Robert M., Why Zebras Don't Get Ulcers, New York: W.H. Freeman and Company, 1998.

Sekukla, Wlodzimierz, Katarina Babinska and Stefka Petrova, "Nutrition Policies in Central and Eastern Europe,” Nutrition Reviews November 1997: (II) S58 - S73. 
Shapiro, Judith, "The Russian Mortality Crisis and Its Causes," in Anders Aslund, editor, Russian Economic Reform in Jeopardy? (London and New York: Pinter Publishers, 1995), 149 - 178.

Shkolnikov, Vladimir M., David A. Leon, Sergey Adamets, Eugeniy Andreev, and Alexander Deev, "Educational Level and Adult Mortality in Russia: An Analysis of Routine Data 1979 to 1994," Social Science and Medicine 47 (3), 1998, 357-369.

Shkolnikov Vladimir M., Martin McKee, David A. Leon, and Laurent Chenet, "Why is the Death Rate from Lung Cancer Falling in the Russian Federation?" European Journal of Epidemiology 1999 (March),15(3):203-6.

Shkolnikov, Vladimir; Martin McKee; and David A. Leon, "Changes in Life Expectancy in Russia in the Mid-1990s," The Lancet 357, March 24, 2001, pp. 917-921.

Shkolnikov, Vladimir; France Meslé; and David A. Leon, "Premature Circulatory Disease Mortality in Russia in Light of Population- and Individual-Level Disease," in Weidner, G., Kopp S.M., and Kristenson, M., editors, Heart Disease: Environment, Stress and Gender (NATO Science Series, Series I: Life and Behavioural Sciences, 2001).

Shkolnikov, V.M., M. McKee, V. V. Chervyakov, and N. A. Kyrianov, "Is the Link Between Alcohol and Cardiovascular Death Among Young Russian Men Attributable to Misclassification of Acute Alcohol Intoxication? Evidence from the City of Izhevsk," Journal of Epidemiology and Community Health 2002, 56: 171-175.

Shleifer, Andrei and Daniel Treisman, “A Normal Country,” NBER Working Paper 10057, October 2003.

Stegmayr, Birgitta; Tatyana Vinogradova; Malyutina, Sofia; Peltonen, Markku; Nikitin, Yuri; Asplund, Kjell, "Widening Gap of Stroke Between East and West: Eight-Year Trends in Occurrence and Risk Factors in Russia and Sweden," Stroke January 2000, 2-8.

Thomas, Duncan and Steven Stillman, "The Effect of Economic Crises on Nutritional Status: Evidence from Russia," unpublished manuscript, 2004.

Twigg, Judyth L., "Balancing the State and the Market: Russia's Adoption of Obligatory Medical Insurance," Europe-Asia Studies Vol. 50 (4), 1998, 583-602.

Watson, Peggy "Explaining Rising Mortality Among Men in Eastern Europe," Social Science and Medicine 41:7 (1995), 923 - 934.

Zatonski, Witold A., Anthony J. McMichael and John W. Powles, "Ecological study of reasons for sharp decline in mortality from ischaemic heart disease in Poland since 1991," British Medical Journal Vol. 316, 4 April 1998, 1047 - 1051. 
Figure 1. Change in Male Life Expectancy at Birth, 1989 -1994,

Eastern Europe and Former Soviet Union

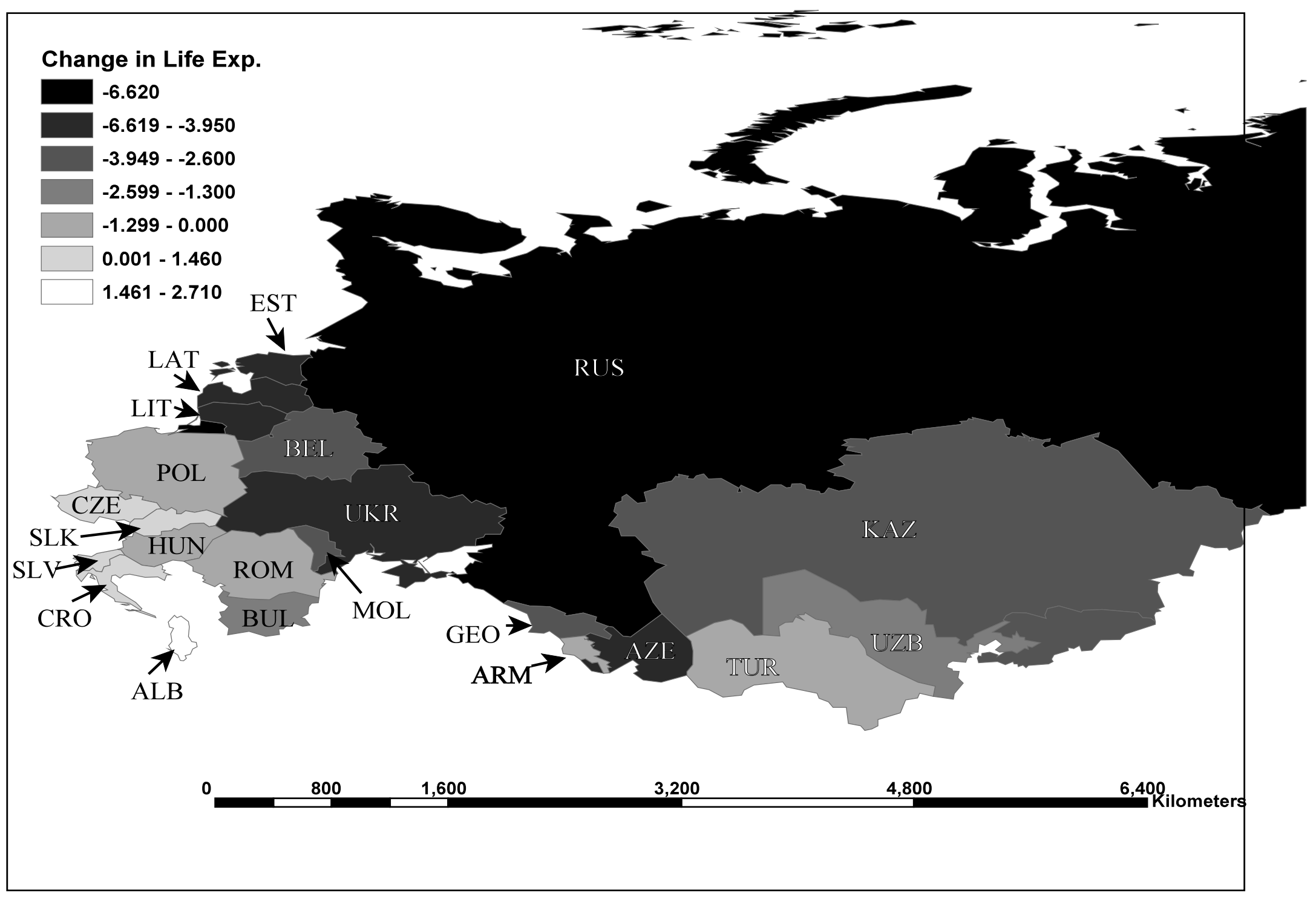


Figure 2a. Trends in male life expectancy at birth, western former Soviet Union, 1958 - 2001

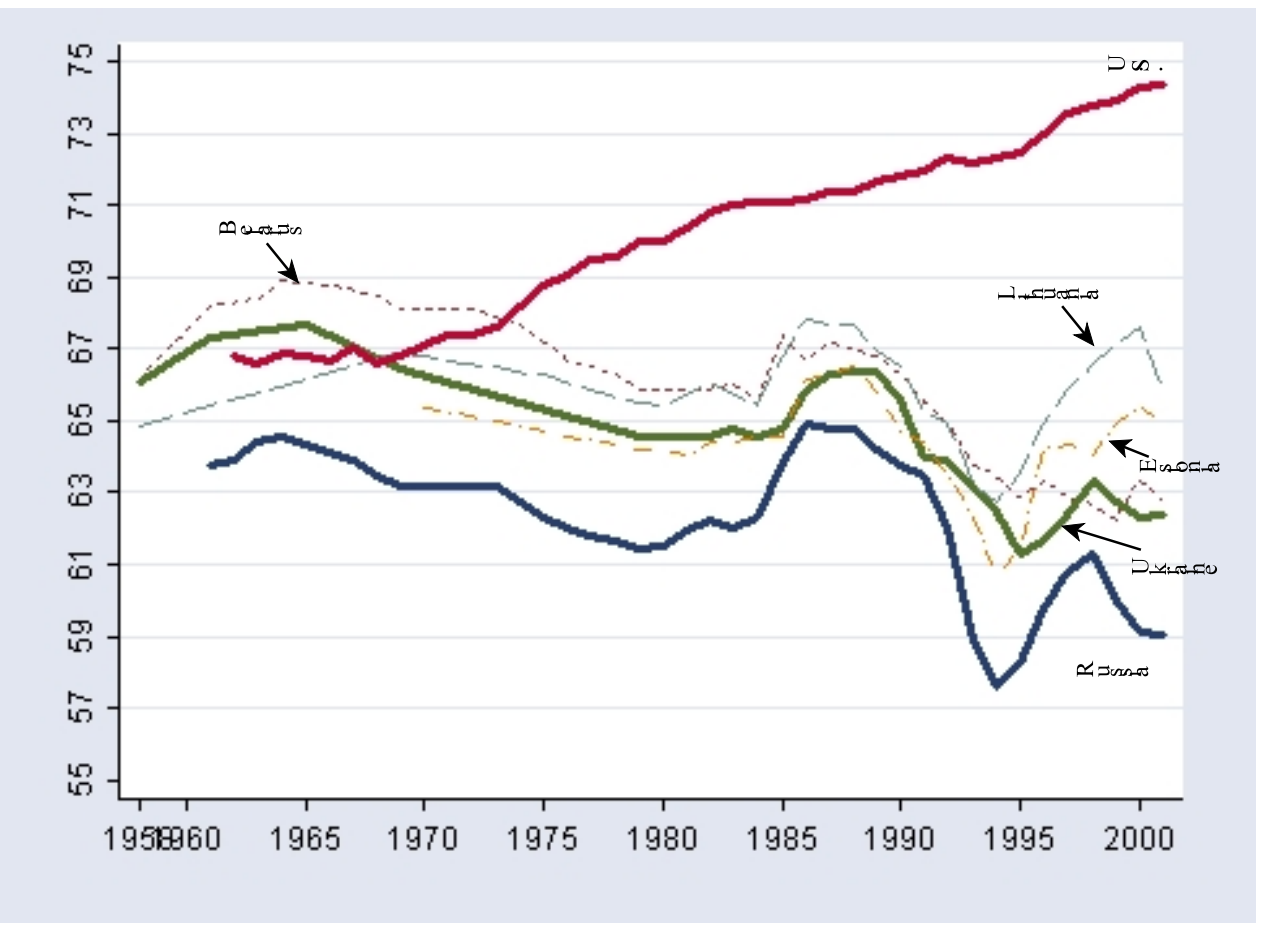

Figure 2b. Trends in male life expectancy at birth, Central Asia, 1960 - 2001

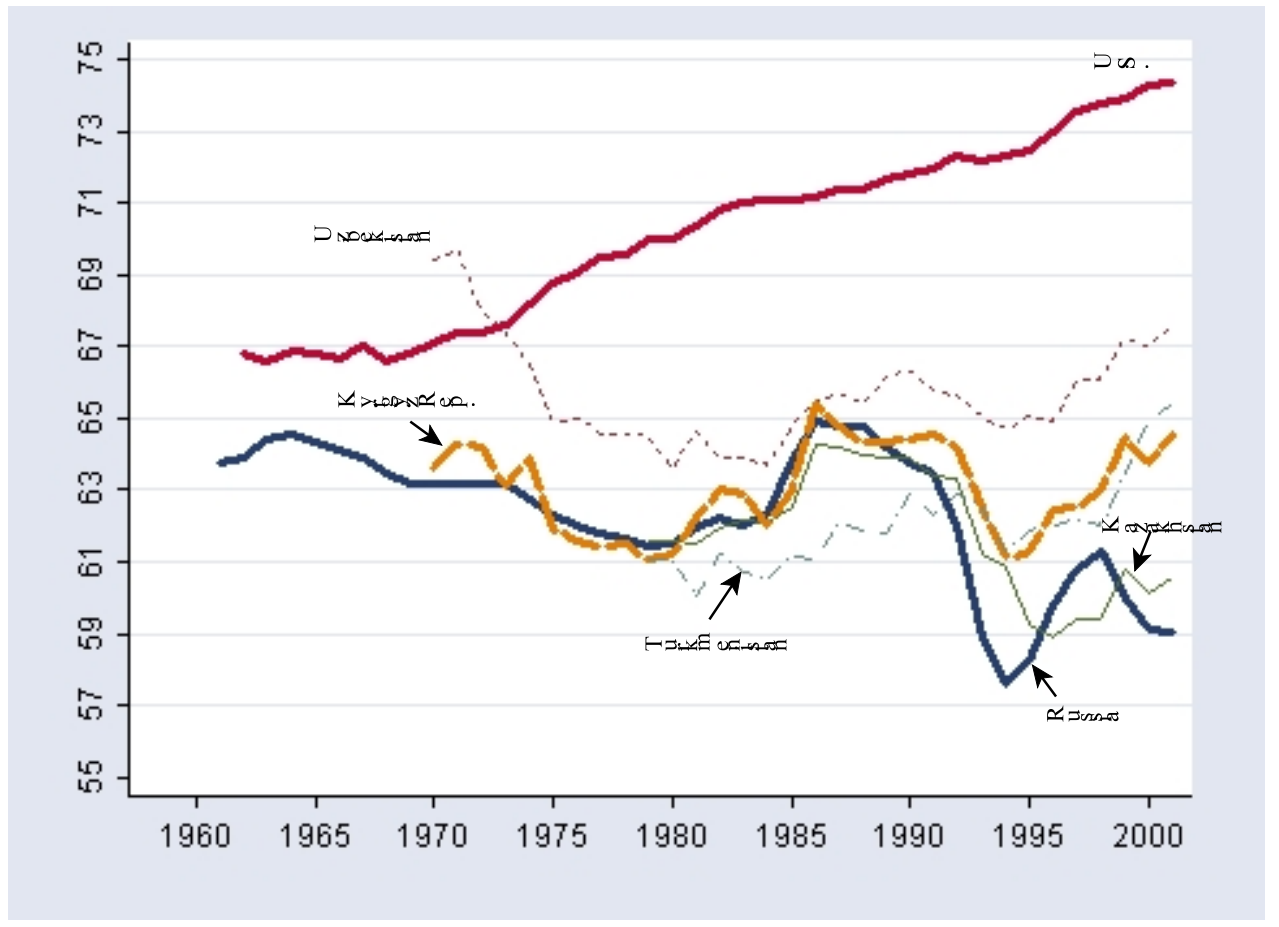


Figure 2c. Trends in male life expectancy at birth, Eastern Europe, 1960 - 2001

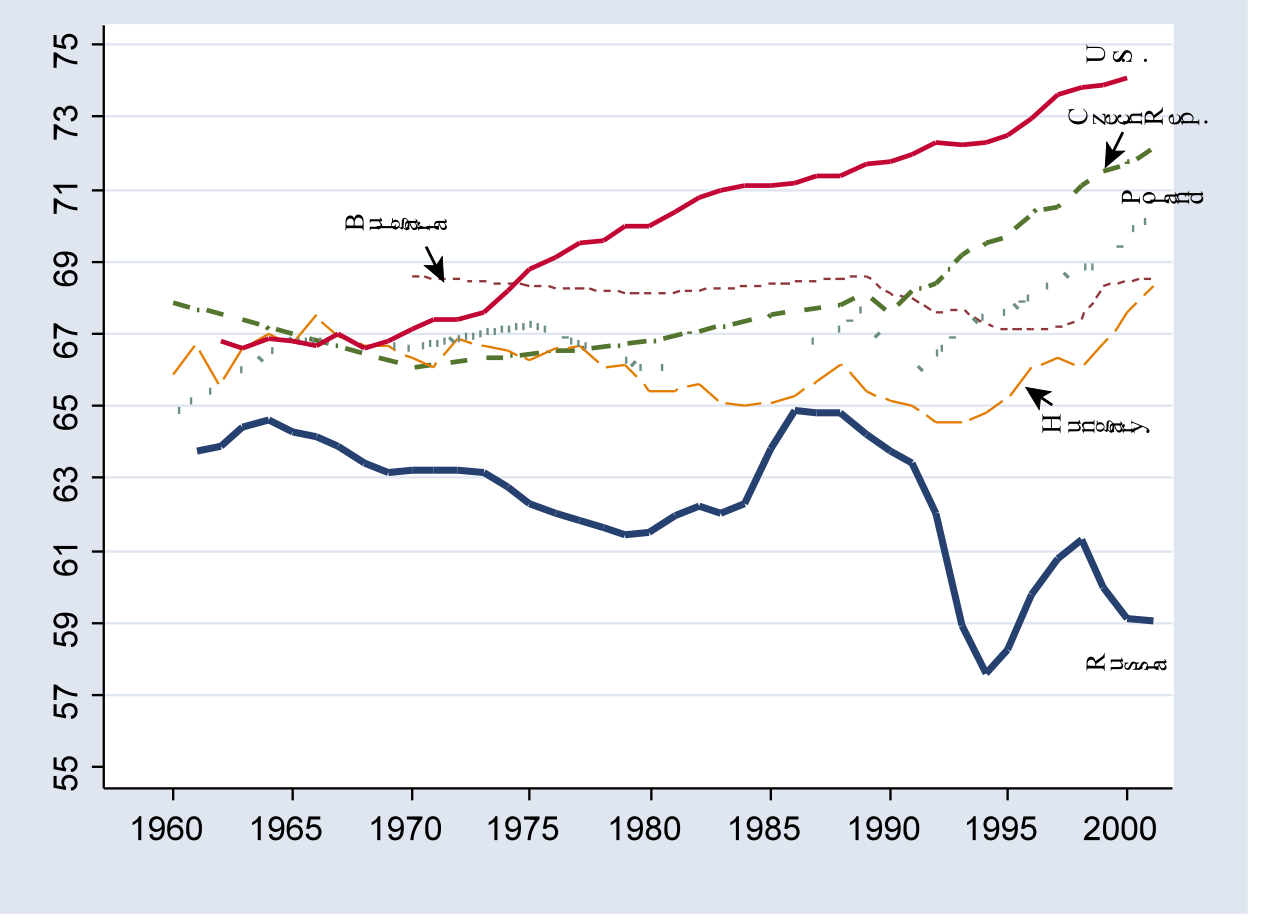


Figure 3. Correlation between log change in male standardized death rate and log change in real GDP per capita
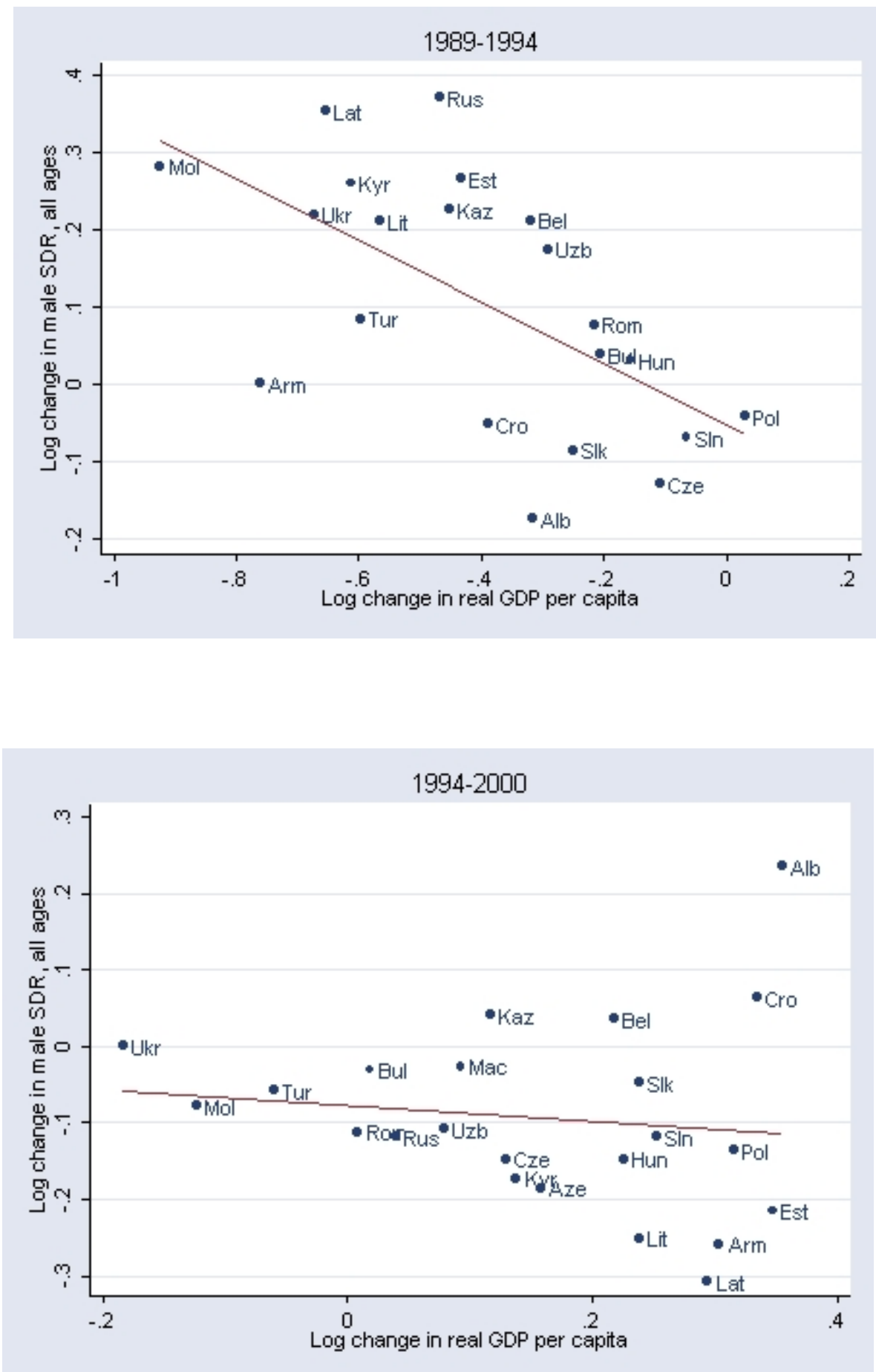
Figure 4. Log change in death rate by age group, Russia, 1989 - 1994

Men

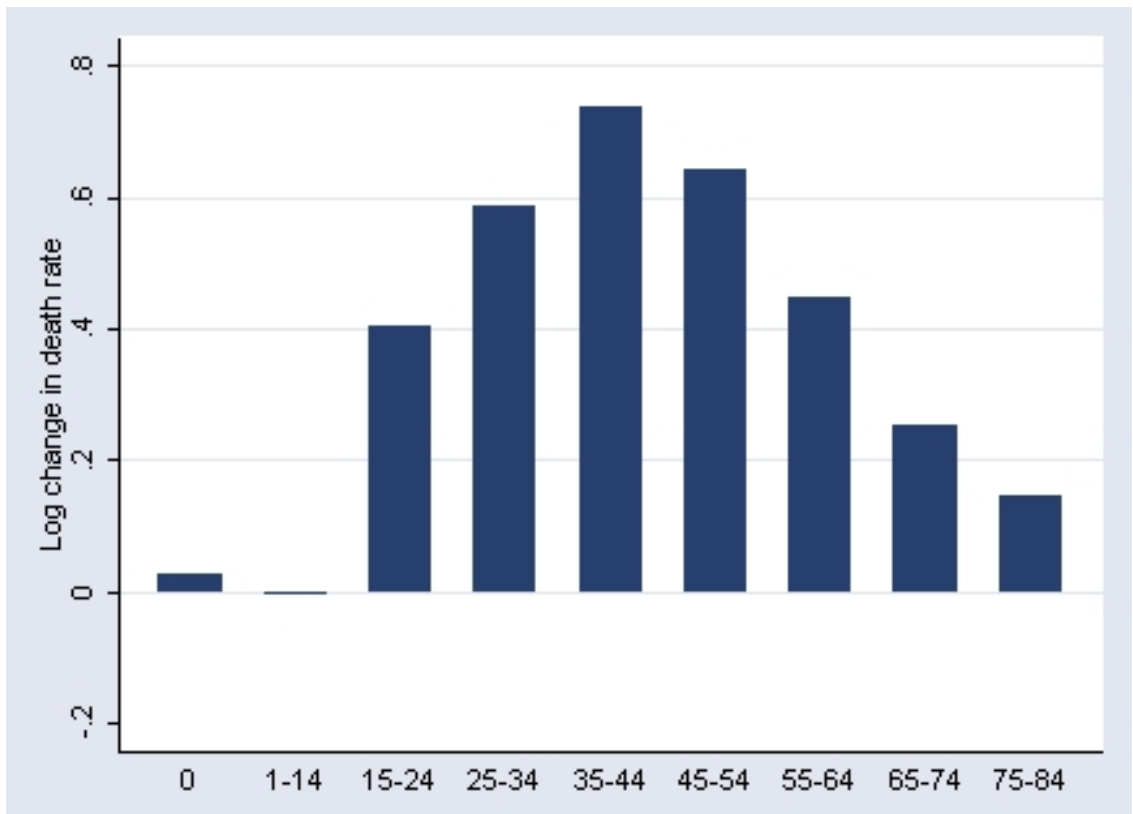

Women

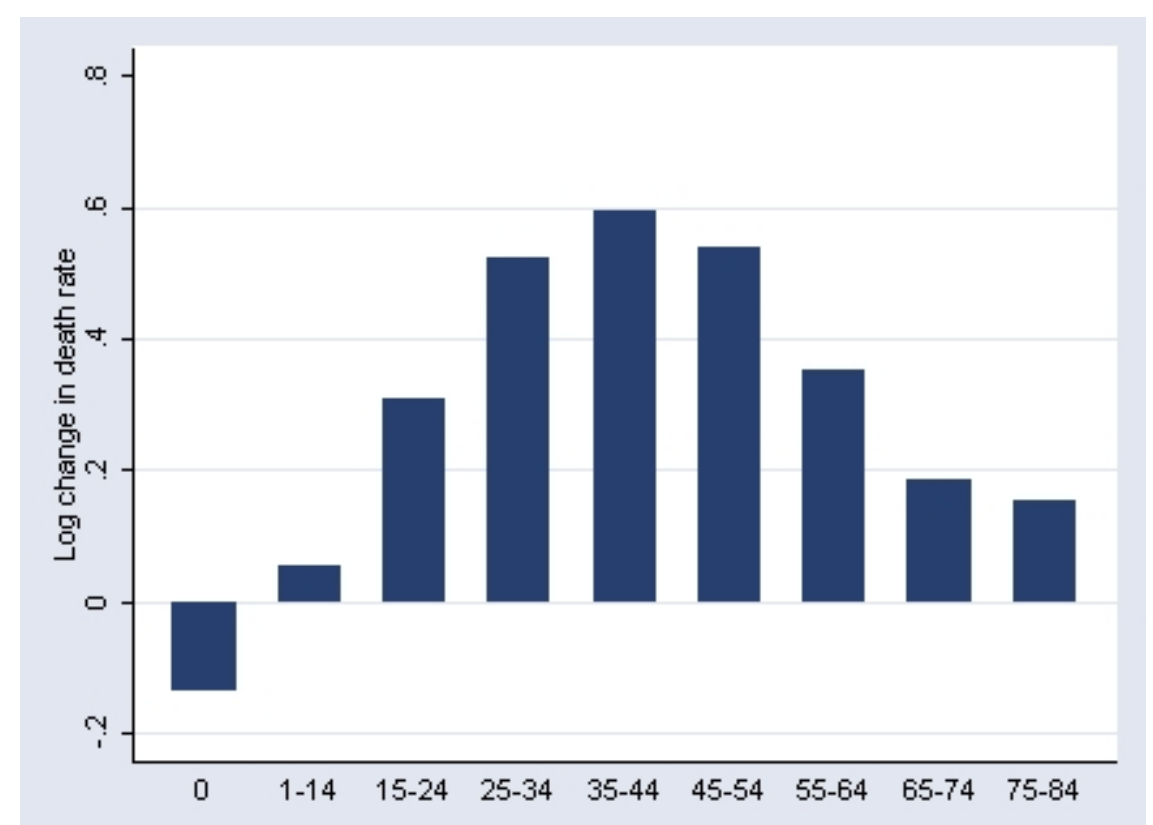


Figure 5. Contribution to change in mortality by cause, all ages, Russia, 1989 - 1994

\section{MEN}

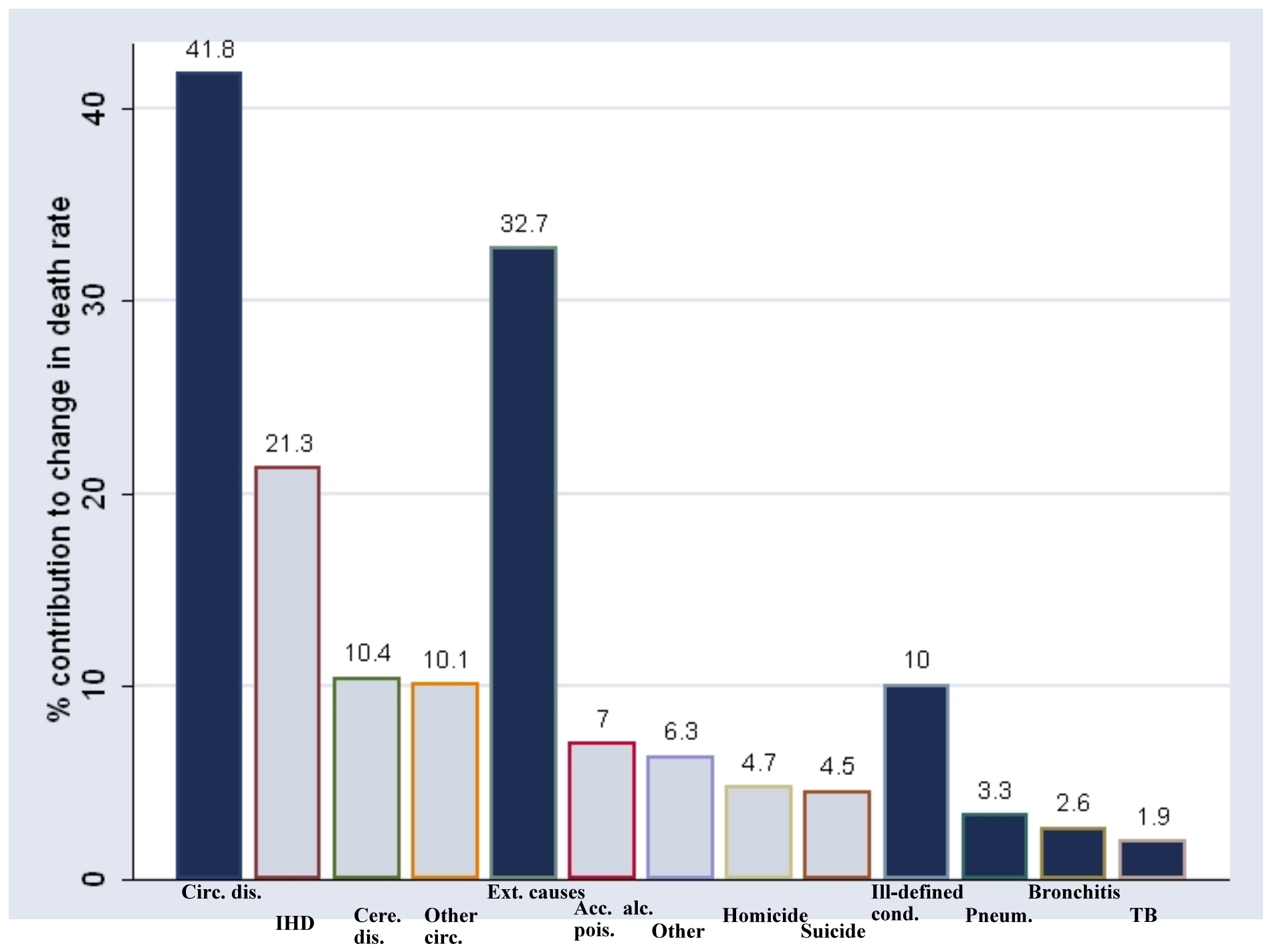


WOMEN

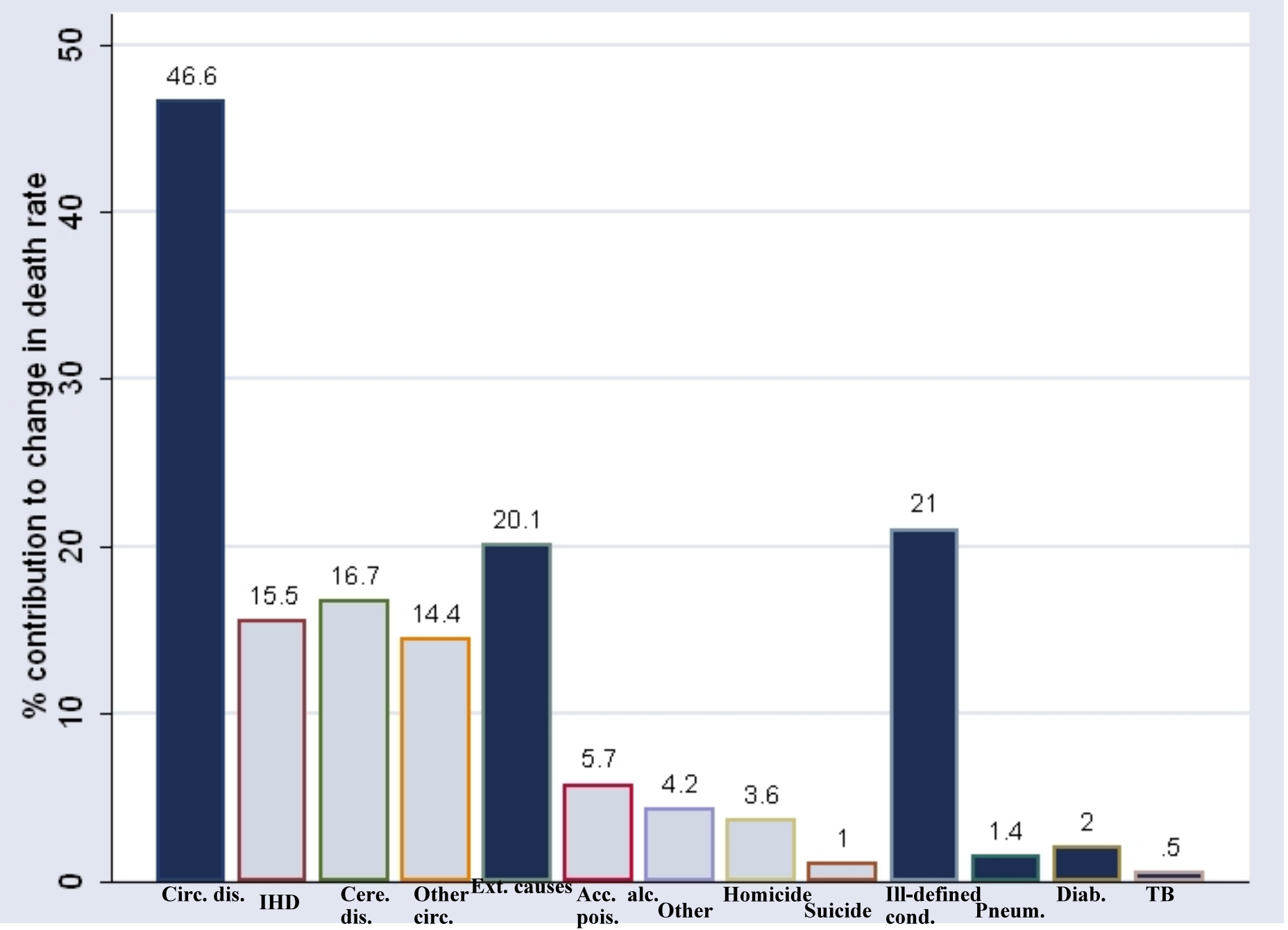


Figure 6. Trends in Overweight and Obesity, Age 25 - 64, RLMS data

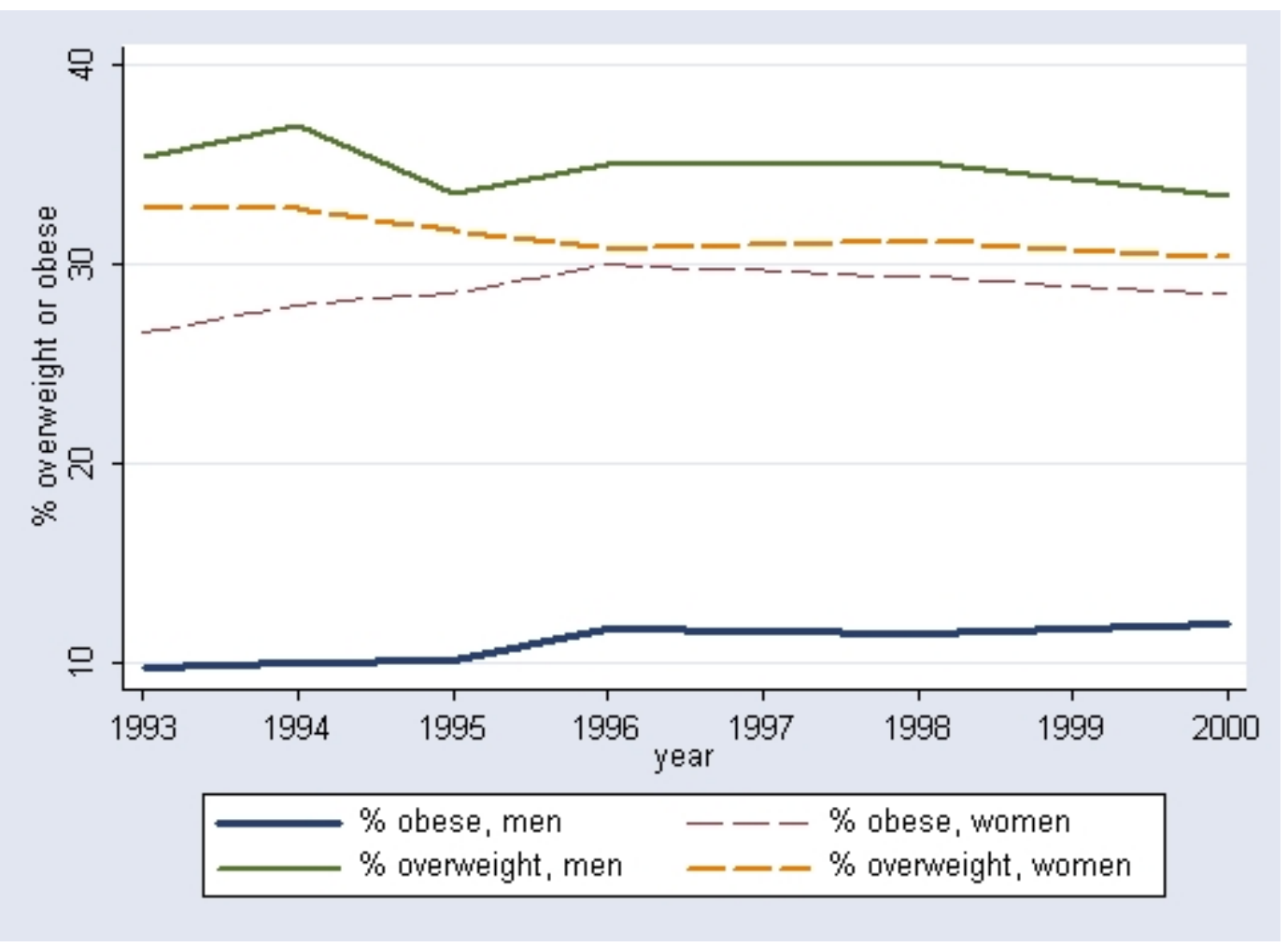

Figure 7. Trends in Smoking Rates, RLMS data

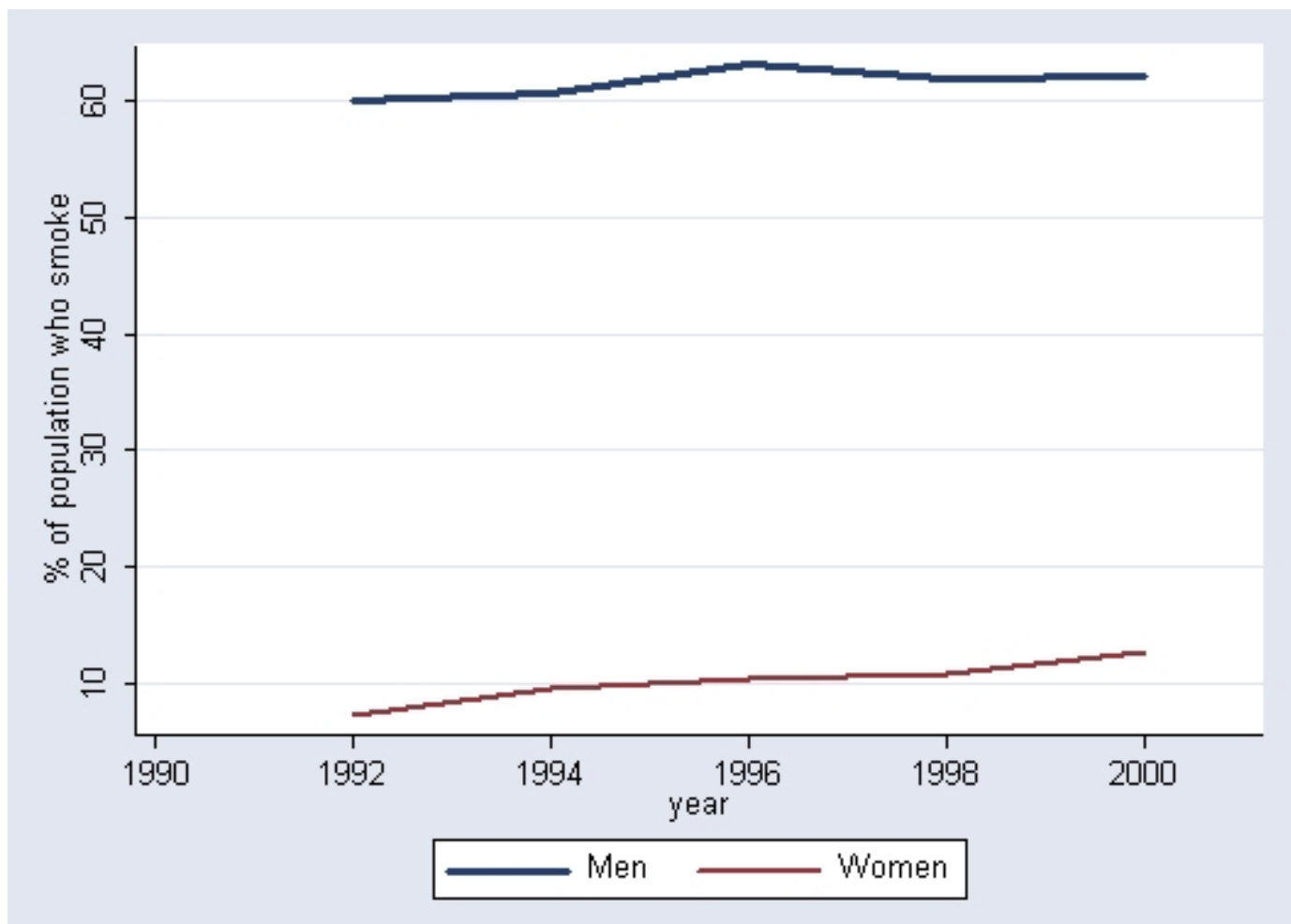


Figure 8. Composition of Alcohol Consumption, Russia and the European Union, 2000

(liters of pure alcohol consumed per capita, age 15+)

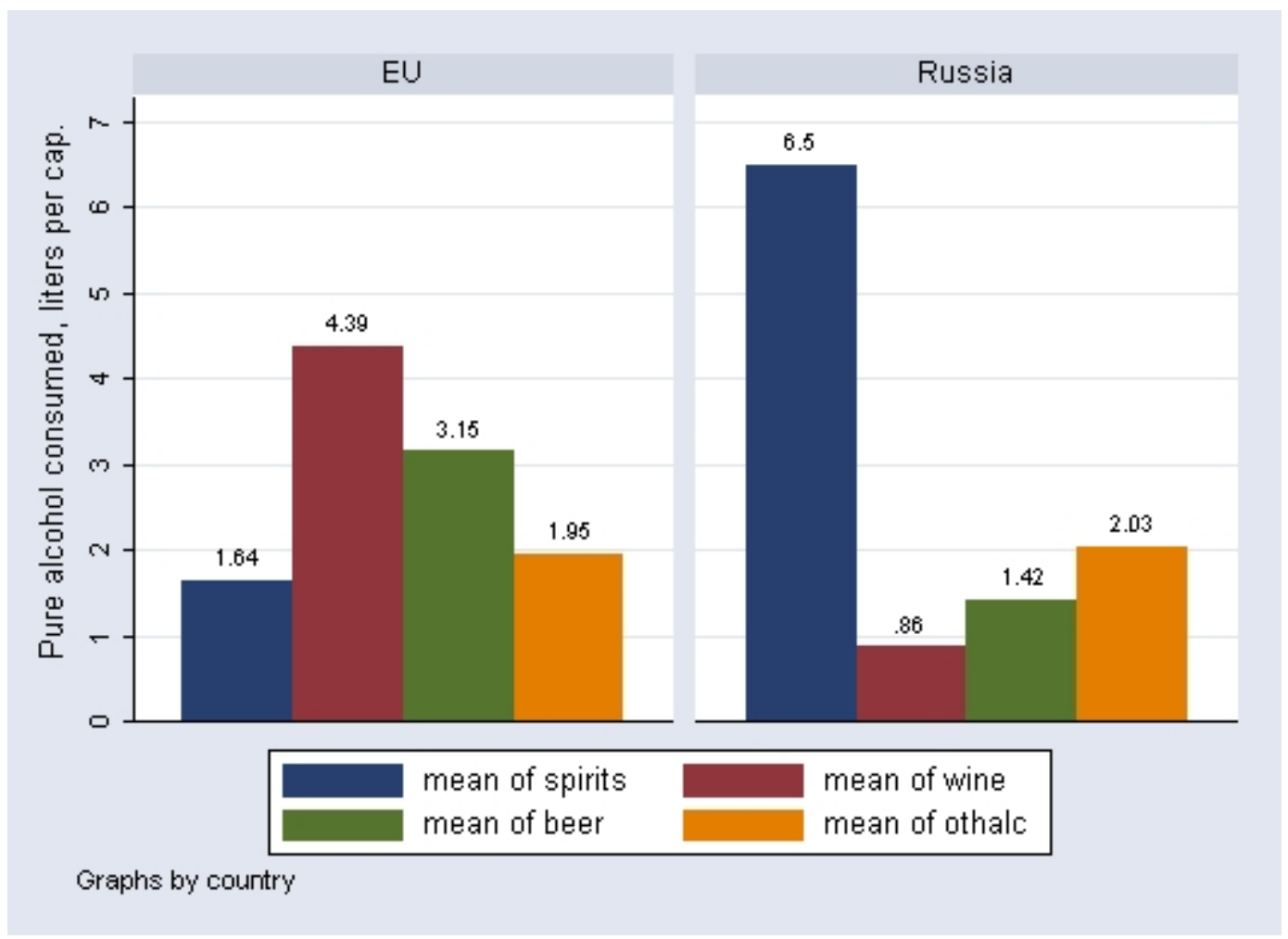

Figure 9. Alcohol Consumption and Male Standardized Death Rate (Age 25-64) in Russia

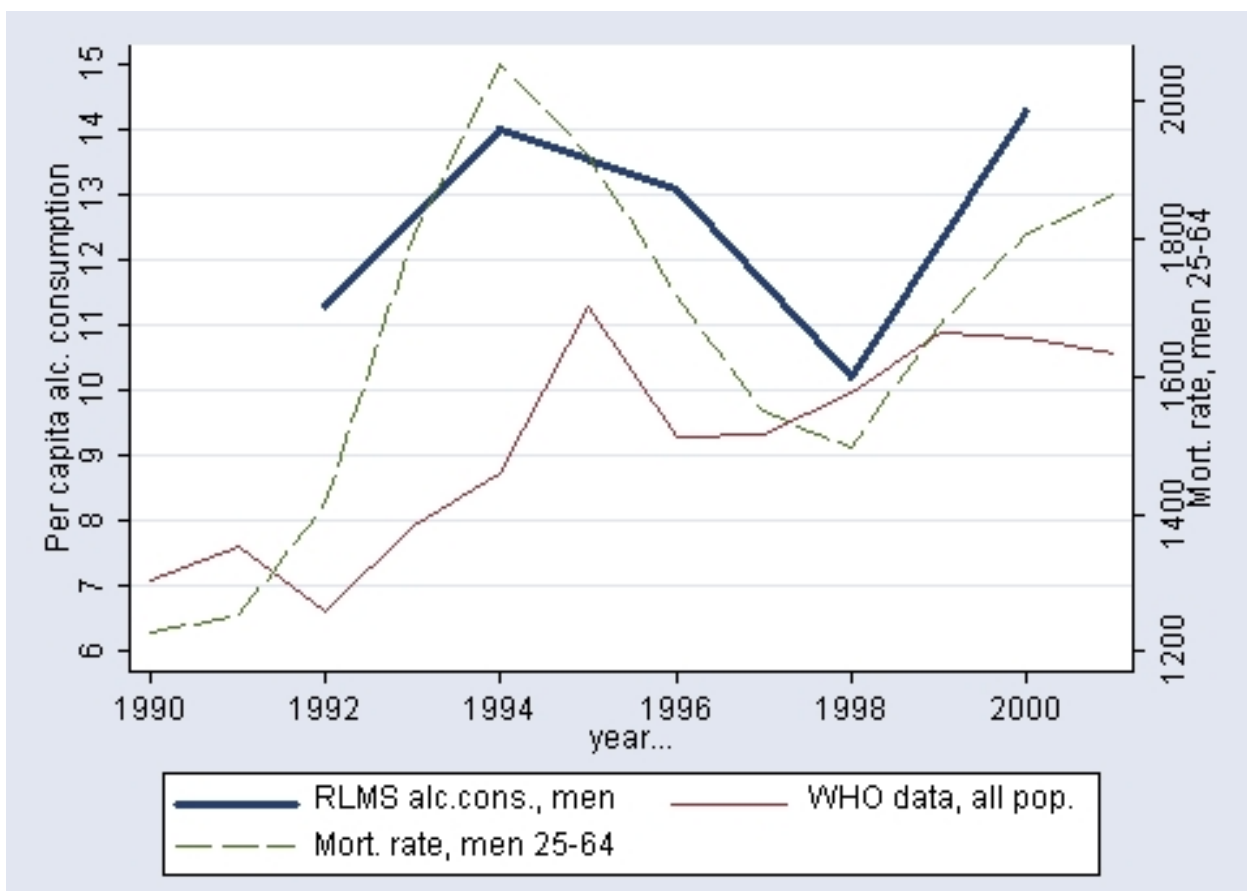


Figure 10. Per Capita Vegetable Consumption (Kilograms Per Year) and Male Life Expectancy at Birth, Russia 1990 - 2000

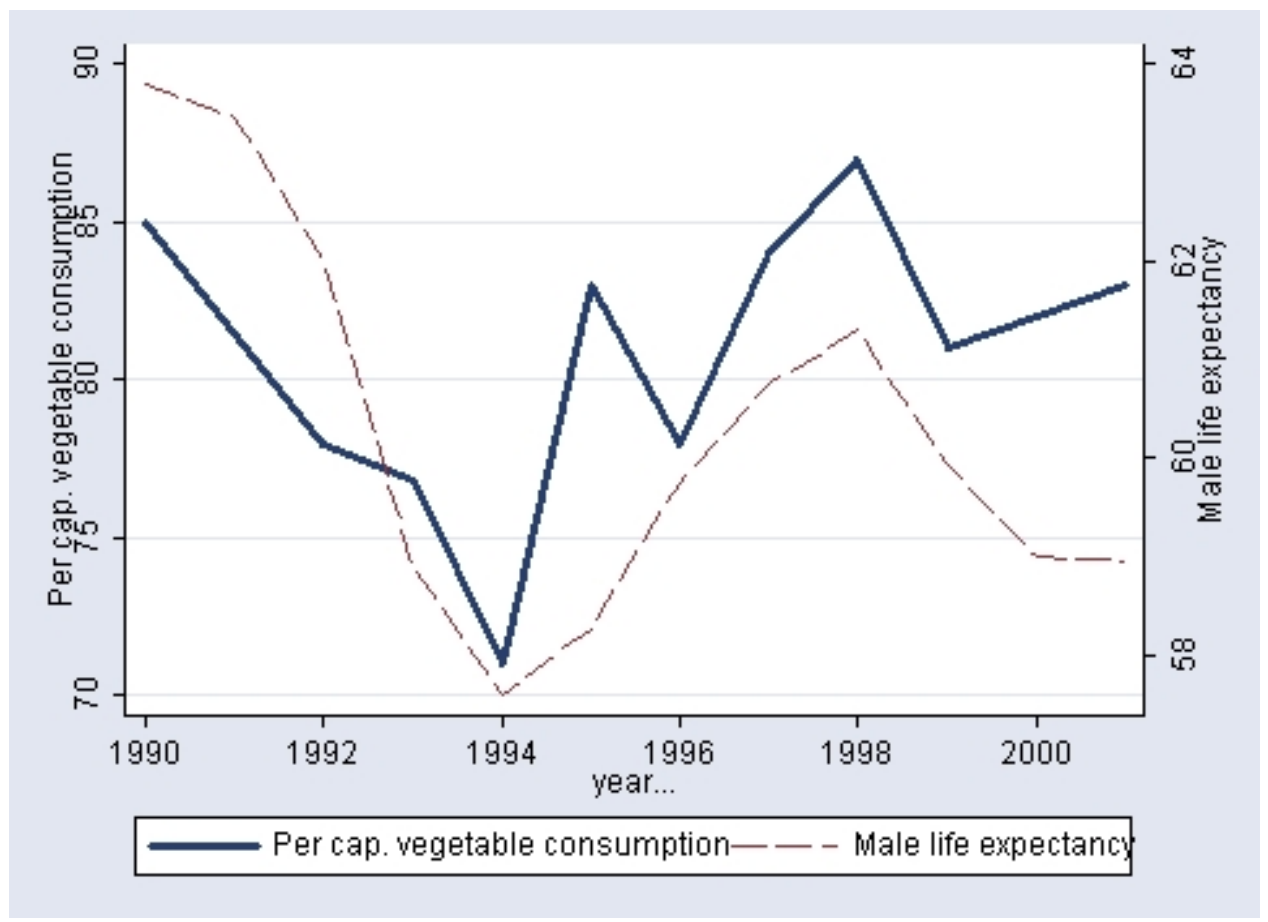

Figure 11. CEEB Expectations Measure By Country, 1992

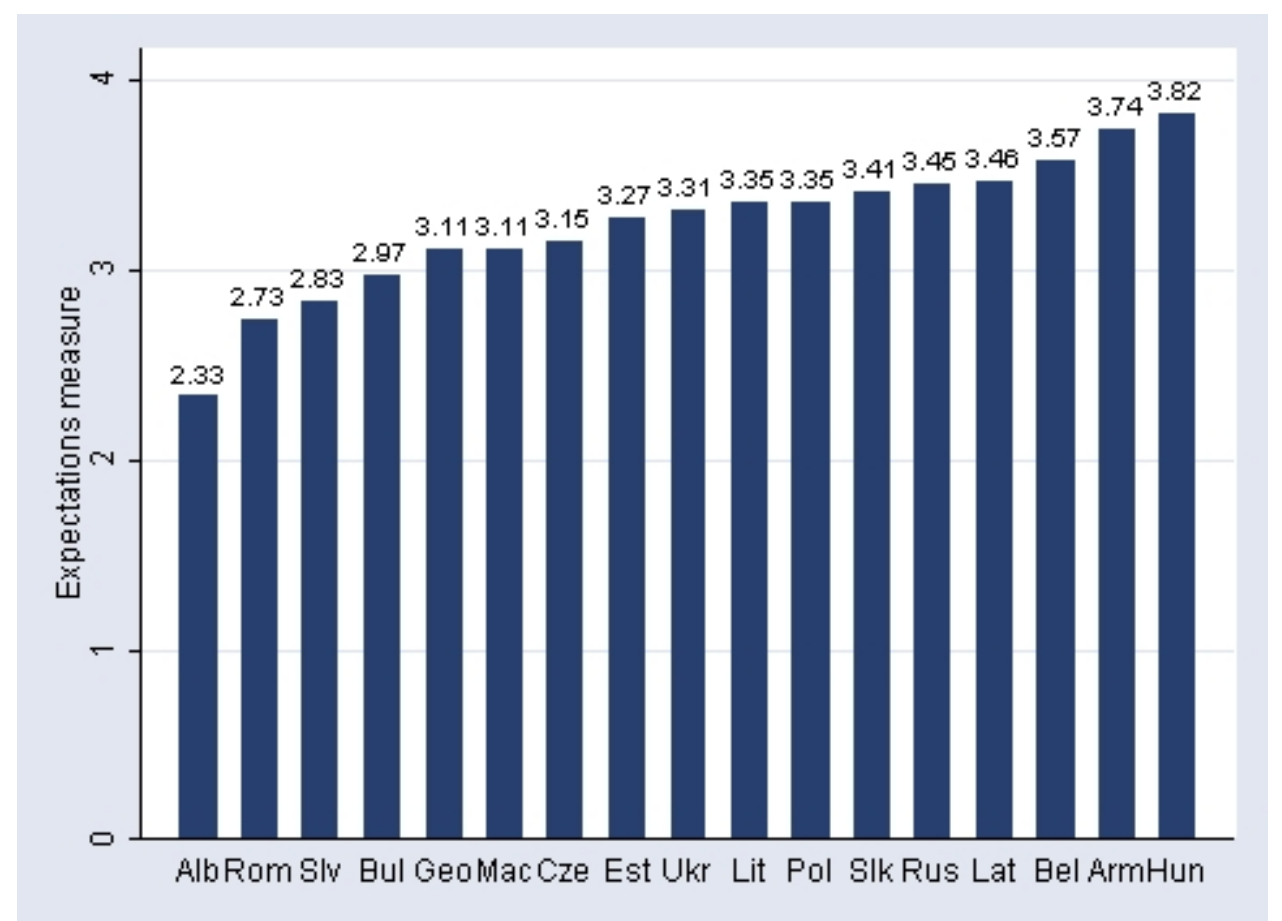


Figure 12. RLMS Expectations Measure By Age

Men

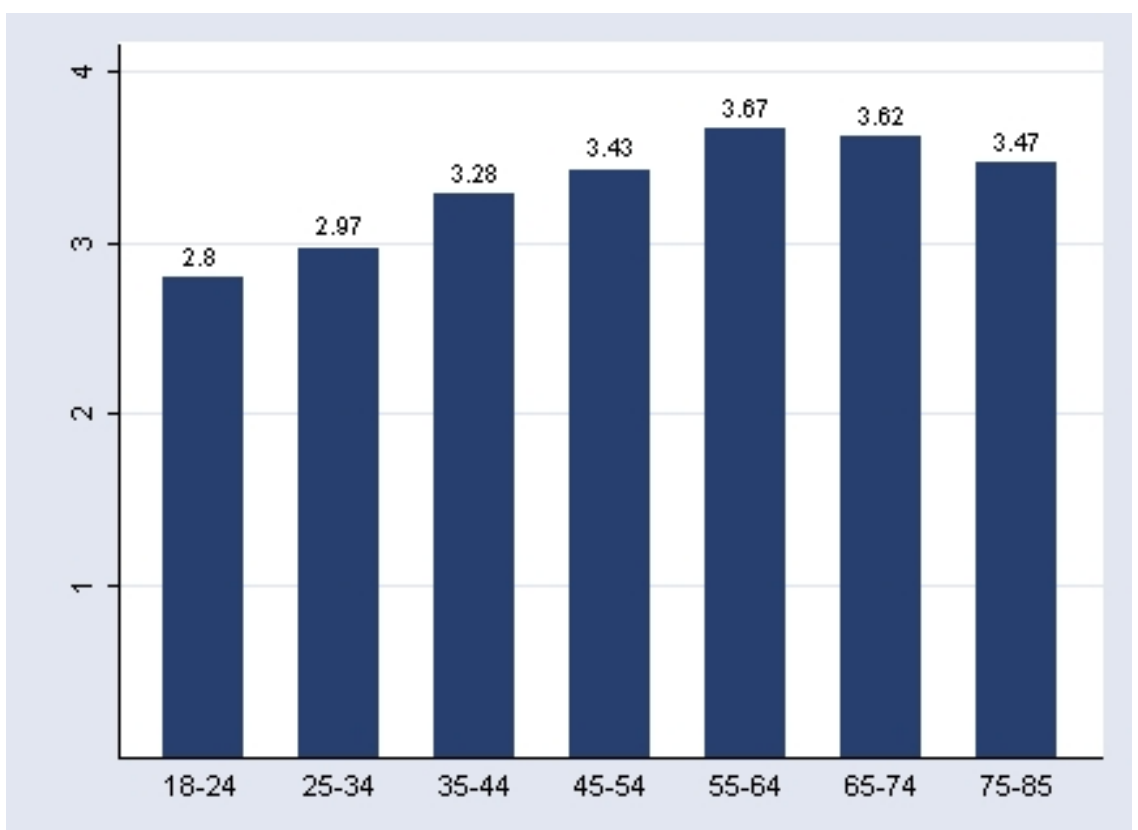

Women

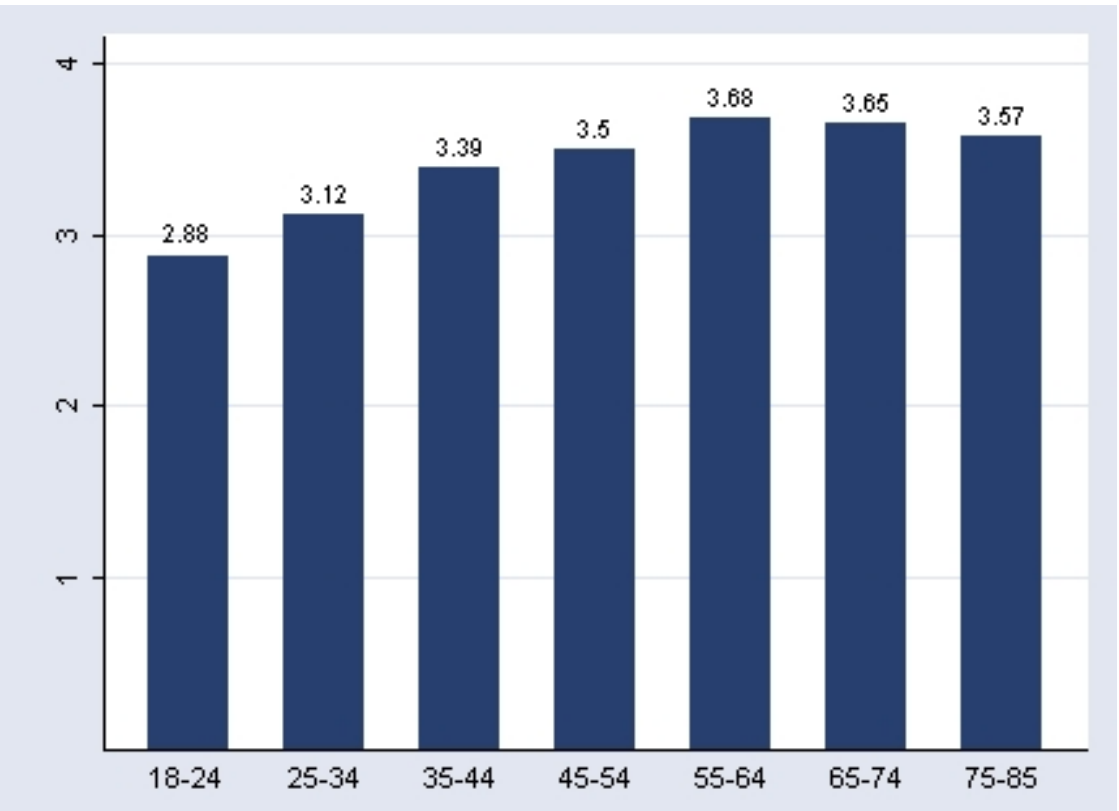


Figure 13. Correlation Between Changes in the Male Standardized Death Rate and the Suicide Rate

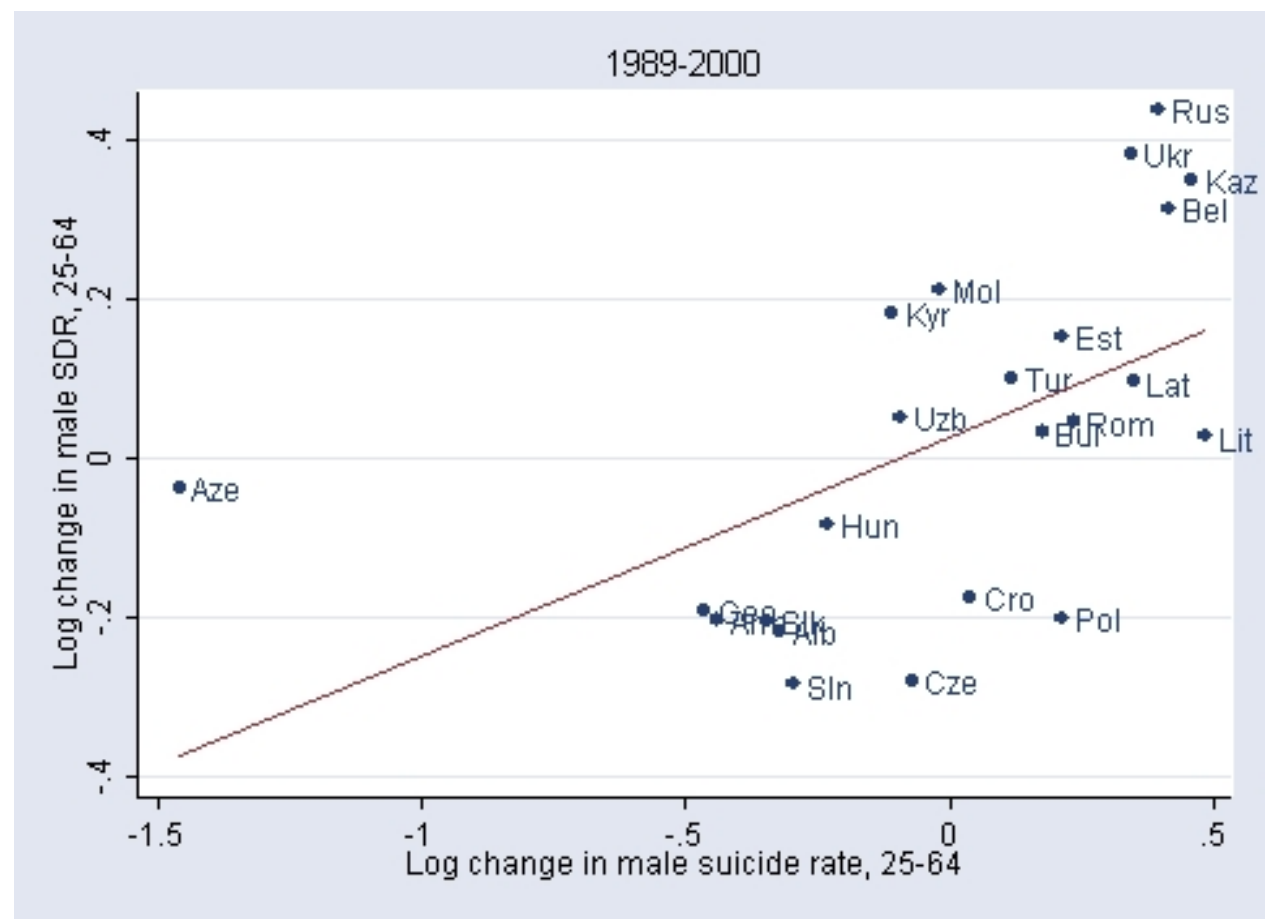

Figure 14. Correlation Between Changes in the Male Standardized Death Rate and Future Expectations

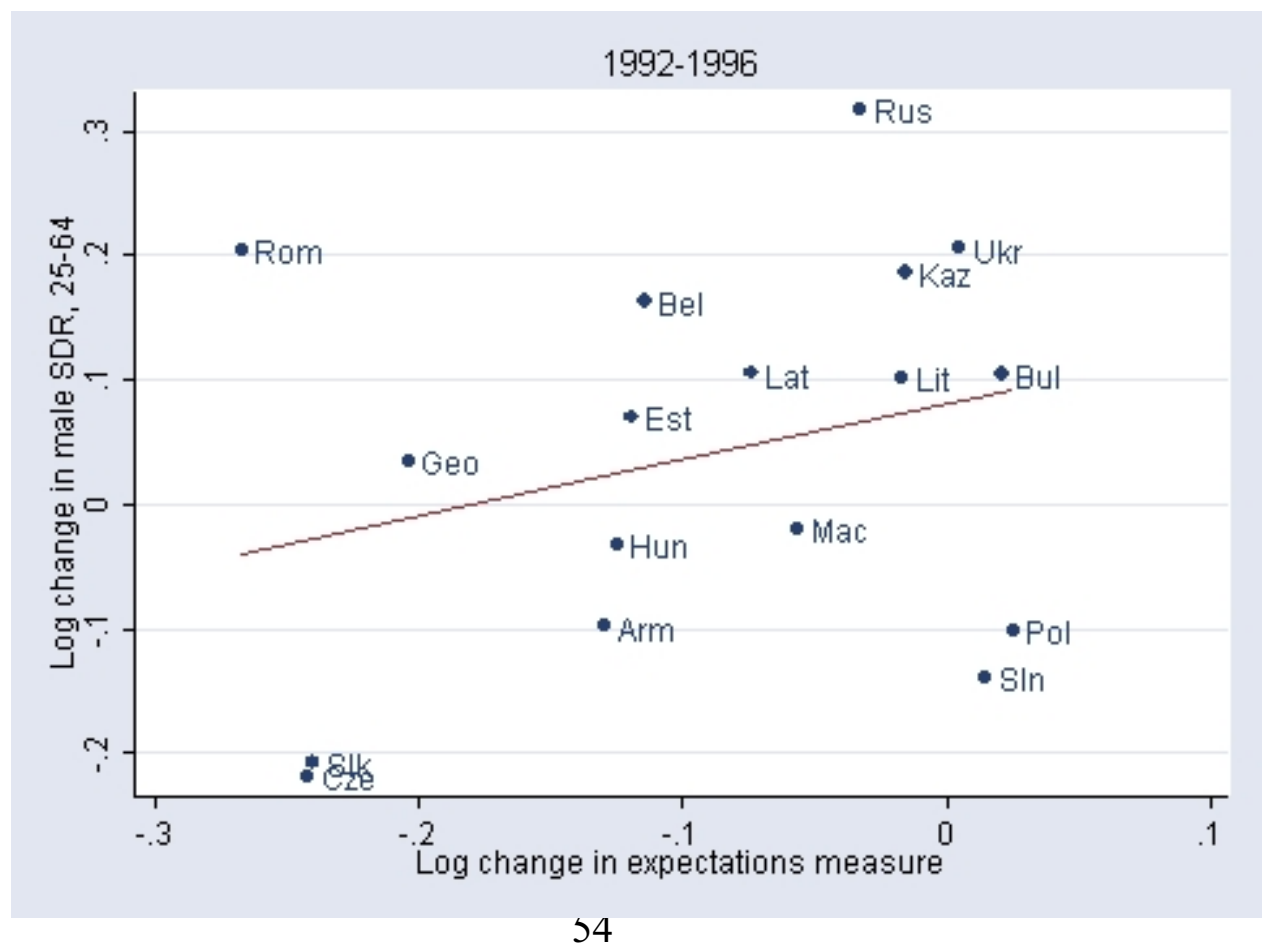


Figure 15. Expectations Measures, Russian Men Age 25-64

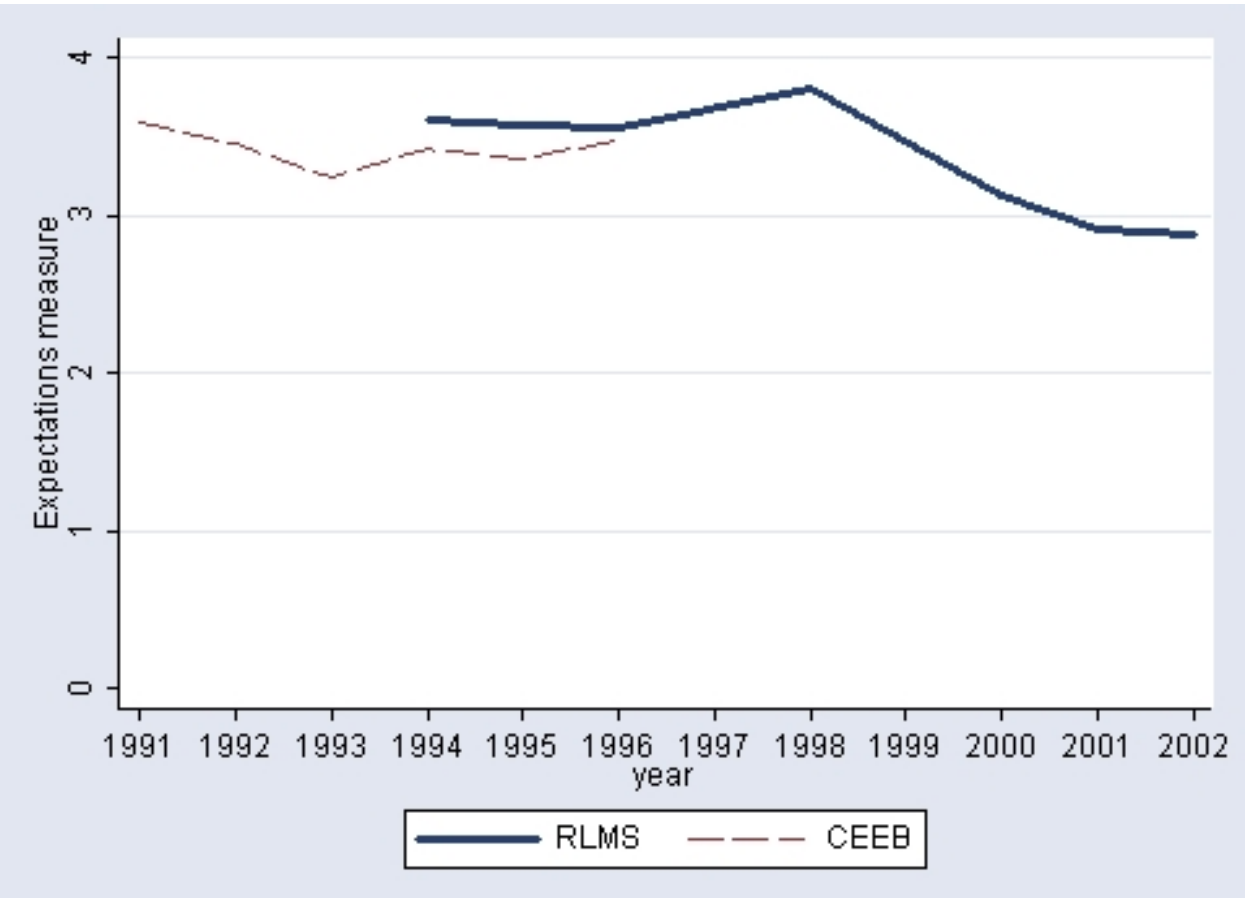


Table 1. Deaths by Level of Education, Russian Longitudinal Monitoring Survey, 1995 - 2002

Age 18 and over

Percentage died

With primary education

With incomplete secondary education

With vocational education

With secondary education

With specialized secondary education

With higher education
$1.58 \%$

5.14

1.79

1.35

0.82

0.70

1.01
Age $30-55$

$0.74 \%$

1.86

1.00

0.82

0.82

0.35

0.23

Table 2. Trends in Payments for Medical Care in Russia

Sample: Individuals who were Hospitalized in the Last 30 Days

\begin{tabular}{lcc|c|c|c|c}
\hline & 1992 & 1993 & 1994 & 1995 & 1996 & 1998 \\
\hline $\begin{array}{l}\text { Percent that paid money for } \\
\text { medical care or treatment }\end{array}$ & 6.2 & 9.6 & 13.9 & 16.1 & 24.2 & 45.4 \\
$\begin{array}{l}\text { Total amount paid, rubles } \\
\text { (median) }\end{array}$ & 2,280 & 12,500 & 57,000 & 100,000 & 170,000 & 300,000 \\
& & & & & & \\
$\begin{array}{l}\text { As \% of median monthly per } \\
\text { capita income }\end{array}$ & 34.2 & 29.1 & 40.7 & 36.6 & 44.2 & 66.7 \\
\end{tabular}

Source: Russian Longitudinal Monitoring Survey, Rounds 1, 3, 5, 6, 7 and 8. 
Table 3. Cross-country Analysis of Factors Leading to Increased Mortality, 1989 - 2000

Dependent variable: log change in standardized mortality rate, all causes, men age 25 - 64

\begin{tabular}{|c|c|c|c|c|c|c|c|}
\hline $\begin{array}{l}\text { Independent Variables } \\
\text { (log changes) }\end{array}$ & (1) & (2) & (3) & (4) & $(5)$ & (6) & (7) \\
\hline \multicolumn{8}{|l|}{ Medical System } \\
\hline Maternal mortality rate & $\begin{array}{l}-.059 \\
(.068)\end{array}$ & & & & & & \\
\hline Public medical spending & & $\begin{array}{l}.087 \\
(.070)\end{array}$ & & & & & \\
\hline Private medical spending & & $\begin{array}{l}.016 \\
(.021)\end{array}$ & & & & & \\
\hline Alcohol Consumption* & & & $\begin{array}{l}.243^{*} \\
(.133)\end{array}$ & & & & \\
\hline $\begin{array}{l}\text { Fruit and Vegetable } \\
\text { Consumption* }\end{array}$ & & & & $\begin{array}{l}-.178 \\
(.121)\end{array}$ & & & \\
\hline \multicolumn{8}{|l|}{ Expectations and stress } \\
\hline Male suicide rate & & & & & $\begin{array}{l}.274 * \\
(.138)\end{array}$ & & \\
\hline Survey expectations** & & & & & & $\begin{array}{l}.452 \\
(.483)\end{array}$ & \\
\hline Minimum wage/average wage & & & & & & & $\begin{array}{r}-.098 * \\
(.051)\end{array}$ \\
\hline $\mathrm{N}$ & 22 & 22 & 22 & 23 & 23 & 17 & 18 \\
\hline $\mathrm{R}^{2}$ & .036 & .112 & .135 & .095 & .287 & .082 & .133 \\
\hline
\end{tabular}

Note: Robust standard errors are reported in parentheses.

* Change between 1992 and 2000 for most countries.

** Change between 1991/1992 and 1996 for most countries. 
Table 4. Logistic Regressions for Men Age 18 and Over Dying in the

Russian Longitudinal Monitoring Survey, 1994-2002

[dependent variable: dummy variable for whether the person died]

\begin{tabular}{|c|c|c|c|c|c|c|c|}
\hline $\begin{array}{l}\text { Independent } \\
\text { variable }\end{array}$ & (1) & (2) & (3) & (4) & (5) & (6) & (7) \\
\hline Age & $\begin{array}{l}1.06^{* * * *} \\
(12.3)\end{array}$ & $\begin{array}{l}1.06 * * * \\
(12.4)\end{array}$ & $\begin{array}{l}1.06 * * * \\
(12.3)\end{array}$ & $\begin{array}{l}1.06^{* * *} \\
(12.3)\end{array}$ & $\begin{array}{l}1.06^{* * *} \\
(12.7)\end{array}$ & $\begin{array}{l}1.06 * * * \\
(12.0)\end{array}$ & $\begin{array}{l}1.06 * * * \\
(12.4)\end{array}$ \\
\hline $\begin{array}{l}\text { Log(income per } \\
\text { capita) }\end{array}$ & $\begin{array}{l}-.903^{*} \\
(1.75)\end{array}$ & $\begin{array}{l}-.902 * \\
(1.77)\end{array}$ & $\begin{array}{l}-.905^{*} \\
(1.70)\end{array}$ & $\begin{array}{l}-.904^{*} \\
(1.73)\end{array}$ & $\begin{array}{l}-.920 \\
(1.40)\end{array}$ & $\begin{array}{l}-.906^{*} \\
(1.70)\end{array}$ & $\begin{array}{l}-.906^{*} \\
(1.68)\end{array}$ \\
\hline $\begin{array}{l}\text { Poor health } \\
(1=\text { yes })\end{array}$ & $\begin{array}{l}2.26^{* * * *} \\
(6.34)\end{array}$ & $\begin{array}{l}2.27 * * * \\
(6.39)\end{array}$ & $\begin{array}{l}2.25 * * * \\
(6.26)\end{array}$ & $\begin{array}{l}2.25 * * * \\
(6.28)\end{array}$ & $\begin{array}{l}2.31 * * * \\
(6.47)\end{array}$ & $\begin{array}{l}2.26 * * * \\
(6.35)\end{array}$ & $\begin{array}{l}2.27 * * * \\
(6.34)\end{array}$ \\
\hline BMI & $\begin{array}{l}-.729 * * * \\
(3.66)\end{array}$ & $\begin{array}{l}-.729 * * * \\
(3.63)\end{array}$ & $\begin{array}{l}-.729 * * * \\
(3.64)\end{array}$ & $\begin{array}{l}-.729 * * * \\
(3.66)\end{array}$ & $\begin{array}{l}-.732 * * * \\
(3.65)\end{array}$ & $\begin{array}{l}-.729 * * * \\
(3.62)\end{array}$ & $\begin{array}{l}-.728 * * * \\
(3.64)\end{array}$ \\
\hline BMI squared & $\begin{array}{l}1.005^{* * * *} \\
(3.38)\end{array}$ & $\begin{array}{l}1.01 * * * \\
(3.35)\end{array}$ & $\begin{array}{l}1.01 * * * \\
(3.35)\end{array}$ & $\begin{array}{l}1.01 * * * \\
(3.38)\end{array}$ & $\begin{array}{l}1.01 * * * \\
(3.39)\end{array}$ & $\begin{array}{l}1.01 * * * \\
(3.32)\end{array}$ & $\begin{array}{l}1.01 * * * \\
(3.36)\end{array}$ \\
\hline $\begin{array}{l}\text { Ever had a heart } \\
\text { attack }\end{array}$ & $\begin{array}{l}1.50 * * \\
(2.31)\end{array}$ & $\begin{array}{l}1.51 * * \\
(2.34)\end{array}$ & $\begin{array}{l}1.50 * * \\
(2.30)\end{array}$ & $\begin{array}{l}1.50 * * \\
(2.29)\end{array}$ & $\begin{array}{l}1.53 * * \\
(2.39)\end{array}$ & $\begin{array}{l}1.52 * * \\
(2.37)\end{array}$ & $\begin{array}{l}1.51 * * \\
(2.36)\end{array}$ \\
\hline Diabetic & $\begin{array}{l}1.76 * * * \\
(2.44)\end{array}$ & $\begin{array}{l}1.77 * * * \\
(2.48)\end{array}$ & $\begin{array}{l}1.76 * * * \\
(2.45)\end{array}$ & $\begin{array}{l}1.76 * * * \\
(2.42)\end{array}$ & $\begin{array}{l}1.79 * * * \\
(2.52)\end{array}$ & $\begin{array}{l}1.78 * * * \\
(2.49)\end{array}$ & $\begin{array}{l}1.77 * * \\
(2.48)\end{array}$ \\
\hline $\begin{array}{l}\text { Ever had a } \\
\text { stroke }\end{array}$ & $\begin{array}{l}1.79 * * * \\
(2.68)\end{array}$ & $\begin{array}{l}1.81 * * * \\
(2.74)\end{array}$ & $\begin{array}{l}1.80 * * * \\
(2.70)\end{array}$ & $\begin{array}{l}1.79 * * * \\
(2.67)\end{array}$ & $\begin{array}{l}1.83 * * * \\
(2.78)\end{array}$ & $\begin{array}{l}1.80^{* * *} \\
(2.72)\end{array}$ & $\begin{array}{l}1.82 * * * \\
(2.74)\end{array}$ \\
\hline Smoker & $\begin{array}{l}1.60 * * * \\
(3.80)\end{array}$ & $\begin{array}{l}1.57 * * * \\
(3.62)\end{array}$ & $\begin{array}{l}1.60 * * * \\
(3.72)\end{array}$ & $\begin{array}{l}1.61 * * * \\
(3.77)\end{array}$ & $\begin{array}{l}1.56 * * * \\
(3.53)\end{array}$ & $\begin{array}{l}1.56 * * * \\
(3.59)\end{array}$ & $\begin{array}{l}1.57 * * * \\
(3.62)\end{array}$ \\
\hline $\begin{array}{l}\text { Alcohol } \\
\text { consumption }\end{array}$ & - & $\begin{array}{l}1.001 * * \\
(2.25)\end{array}$ & $\begin{array}{l}1.001 * * \\
(2.44)\end{array}$ & - & $\begin{array}{l}1.001 * * \\
(2.16)\end{array}$ & $\begin{array}{l}1.001 * * \\
(2.22)\end{array}$ & $\begin{array}{l}1.001 * * \\
(2.25)\end{array}$ \\
\hline Binge drinker & - & - & $\begin{array}{l}-.908 \\
(0.80)\end{array}$ & $\begin{array}{l}-.972 \\
(0.24)\end{array}$ & - & - & - \\
\hline $\begin{array}{l}\text { Positive } \\
\text { expectations }\end{array}$ & - & - & - & - & - & $\begin{array}{l}-.706 \\
(1.59)\end{array}$ & - \\
\hline $\begin{array}{l}\text { In poverty or } \\
\text { extreme poverty }\end{array}$ & - & - & - & - & $\begin{array}{c}1.10 \\
(0.59)\end{array}$ & - & - \\
\hline $\begin{array}{l}\text { Received fuel } \\
\text { subsidies }\end{array}$ & - & - & - & - & $\begin{array}{l}-0.974 \\
(0.06)\end{array}$ & - & - \\
\hline $\begin{array}{l}\text { Sold goods for } \\
\text { food }\end{array}$ & - & - & - & - & $\begin{array}{c}1.19 \\
(0.69)\end{array}$ & - & - \\
\hline $\begin{array}{l}\% \text { expenditures } \\
\text { on food }\end{array}$ & - & - & - & - & $\begin{array}{c}1.15 \\
(0.48)\end{array}$ & - & - \\
\hline
\end{tabular}




\begin{tabular}{l|ccccccc}
$\begin{array}{l}\text { Min. wage as \% } \\
\text { of average wage }\end{array}$ & - & - & - & - & - & - & 1.01 \\
& & & & & & & \\
No. died & 432 & 432 & 432 & 432 & 432 & 432 & 432 \\
$\mathrm{~N}$ & 17092 & 17092 & 17092 & 17092 & 17092 & 17092 & 17092 \\
Pseudo R $^{2}$ & .163 & .165 & .165 & .163 & .165 & .165 & .165 \\
\hline \hline
\end{tabular}

Coefficients are reported as odds ratios. Z-statistics in parentheses. Standard errors are calculated using the Huber/White method and are corrected for individual clustering. All regressions include controls for marital status, education level, year of the survey, and large region (North, Central, Volga, North Caucuses, Urals, West Siberia, East Siberia, Moscow/St. Petersburg). A binge drinker is defined as someone who reports their 'usual' alcohol consumption in the last 30 days as 120 grams or more of hard alcohol per day.

*** Statistically significant at the 1 percent level or less.

** Statistically significant at the 5percent level or less.

* Statistically significant at the 10 percent level or less. 
Table 5. Analysis of Cross Country Mortality, by Cause, 1989 - 2000 Dependent variable: log change in standardized mortality rate, men age 25 - 64

\begin{tabular}{lccc}
$\begin{array}{l}\text { Independent Variables } \\
\text { (log changes): }\end{array}$ & $\begin{array}{c}\text { External } \\
\text { Causes }\end{array}$ & $\begin{array}{c}\text { Cardiovascular } \\
\text { Disease }\end{array}$ & $\begin{array}{c}\text { All Other } \\
\text { Causes }\end{array}$ \\
\hline Alcohol consumption* & .432 & .221 & $.177^{*}$ \\
$\mathrm{~N}$ & $(.379)$ & $(.137)$ & $(.093)$ \\
$\mathrm{R} 2$ & 22 & 22 & 22 \\
& .084 & .079 & .107 \\
Fruit and Vegetable & -.145 & & \\
Consumption* & $(.304)$ & $-.277^{* *}$ & -.171 \\
$\mathrm{~N}$ & 23 & $(.123)$ & $(.137)$ \\
R2 & .008 & 23 & 22 \\
& & .095 & .090
\end{tabular}

Expectations and stress

Male suicide rate** $.590 * * *$

$\mathrm{N}$

23

23

23

R2

.354

.125

.281

Survey expectations***

.886

.338

.355

$(.525)$

(.605)

(.430)

$\mathrm{N}$

17

17

17

$\mathrm{R}^{2}$

.121

.031

.070

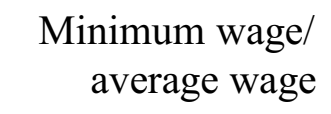

$-.013$

$(.098)$

$-.184 * * *$

$-.061 *$

average wage

18

18

N

.001

.261

18

.109 
Note: Robust standard errors are reported in parentheses.

* Change between 1992 and 2000 for most countries.

** For the external causes regression, the dependent variable is the mortality rate for all causes minus the suicide mortality rate.

***Change between 1991/1992 and 1996 for most countries. 
Table 6. Logistic Regressions for Men Age 18 and Over Dying in the Russian Longitudinal Monitoring Survey, By Cause, 2000-2002

\begin{tabular}{|c|c|c|c|c|c|c|c|c|}
\hline \multirow[t]{2}{*}{ DV: } & \multicolumn{4}{|c|}{ Accidental Deaths } & \multicolumn{4}{|c|}{ CVD Deaths } \\
\hline & $(1)$ & $(2)$ & (3) & $(4)$ & (5) & $(6)$ & $(7)$ & $(8)$ \\
\hline Age & $\begin{array}{c}1.02 \\
(1.48)\end{array}$ & $\begin{array}{c}1.02 \\
(1.47)\end{array}$ & $\begin{array}{c}1.02 \\
(1.42)\end{array}$ & $\begin{array}{c}1.02 \\
(1.61)\end{array}$ & $\begin{array}{l}1.08 * * * \\
(5.48)\end{array}$ & $\begin{array}{l}1.08^{* * * *} \\
(5.55)\end{array}$ & $\begin{array}{l}1.08 * * * \\
(5.54)\end{array}$ & $\begin{array}{l}1.08 * * * \\
(5.59)\end{array}$ \\
\hline $\begin{array}{l}\text { Log(income per } \\
\text { capita) }\end{array}$ & $\begin{array}{l}-.629 * * \\
(2.35)\end{array}$ & $\begin{array}{l}-.611^{*} \\
(2.41)\end{array}$ & $\begin{array}{l}-.611^{*} \\
(2.34)\end{array}$ & $\begin{array}{l}-.613 * * \\
(2.31)\end{array}$ & $\begin{array}{l}1.24 \\
(0.81)\end{array}$ & $\begin{array}{l}1.25 \\
(0.81)\end{array}$ & $\begin{array}{l}1.24 \\
(0.80)\end{array}$ & $\begin{array}{l}1.18 \\
(0.64)\end{array}$ \\
\hline $\begin{array}{l}\text { Poor health } \\
(1=\text { yes })\end{array}$ & $\begin{array}{l}-.320 \\
(1.49)\end{array}$ & $\begin{array}{l}-.376 \\
(1.32)\end{array}$ & $\begin{array}{l}-.383 \\
(1.21)\end{array}$ & $\begin{array}{l}-.322 \\
(1.50)\end{array}$ & $\begin{array}{l}1.39 \\
(0.83)\end{array}$ & $\begin{array}{c}1.44 \\
(0.93)\end{array}$ & $\begin{array}{l}1.43 \\
(0.93)\end{array}$ & $\begin{array}{l}1.45 \\
(0.91)\end{array}$ \\
\hline BMI & $\begin{array}{l}-.849 \\
(0.43)\end{array}$ & $\begin{array}{l}-.869 \\
(0.38)\end{array}$ & $\begin{array}{l}-.846 \\
(0.46)\end{array}$ & $\begin{array}{l}-.851 \\
(0.43)\end{array}$ & $\begin{array}{l}-.576 \\
(1.57)\end{array}$ & $\begin{array}{l}-.581 \\
(1.50)\end{array}$ & $\begin{array}{l}-.578 \\
(1.51)\end{array}$ & $\begin{array}{l}-.589 \\
(1.48)\end{array}$ \\
\hline BMI squared & $\begin{array}{l}1.00 \\
(0.33)\end{array}$ & $\begin{array}{l}1.00 \\
(0.29)\end{array}$ & $\begin{array}{c}1.00 \\
(0.38)\end{array}$ & $\begin{array}{l}1.00 \\
(0.33)\end{array}$ & $\begin{array}{c}1.01 \\
(1.49)\end{array}$ & $\begin{array}{c}1.01 \\
(1.43)\end{array}$ & $\begin{array}{c}1.01 \\
(1.42)\end{array}$ & $\begin{array}{c}1.01 \\
(1.40)\end{array}$ \\
\hline $\begin{array}{l}\text { Ever had a heart } \\
\text { attack }\end{array}$ & - & - & - & - & $\begin{array}{l}1.13 \\
(0.23)\end{array}$ & $\begin{array}{l}1.14 \\
(0.27)\end{array}$ & $\begin{array}{l}1.15 \\
(0.27)\end{array}$ & $\begin{array}{l}1.07 \\
(0.13)\end{array}$ \\
\hline Diabetic & - & - & - & - & $\begin{array}{l}4.96 * * * \\
(3.18)\end{array}$ & $\begin{array}{l}5.04 * * * \\
(3.20)\end{array}$ & $\begin{array}{l}5.11 * * * \\
(3.24)\end{array}$ & $\begin{array}{l}4.86 * * * \\
(3.10)\end{array}$ \\
\hline Ever had a stroke & - & - & - & - & $\begin{array}{l}1.75 \\
(0.81)\end{array}$ & $\begin{array}{c}1.74 \\
(0.81)\end{array}$ & $\begin{array}{l}1.76 \\
(0.81)\end{array}$ & $\begin{array}{l}1.66 \\
(0.74)\end{array}$ \\
\hline Smoker & $\begin{array}{c}2.34 \\
(1.60)\end{array}$ & $\begin{array}{c}1.91 \\
(1.27)\end{array}$ & $\begin{array}{c}1.96 \\
(1.35)\end{array}$ & $\begin{array}{c}2.29 \\
(1.56)\end{array}$ & $\begin{array}{l}2.28^{* *} \\
(2.10)\end{array}$ & $\begin{array}{l}2.22 * * \\
(1.95)\end{array}$ & $\begin{array}{l}2.17^{*} \\
(1.90)\end{array}$ & $\begin{array}{l}2.27 * * \\
(2.06)\end{array}$ \\
\hline $\begin{array}{l}\text { Alcohol } \\
\text { consumption }\end{array}$ & $\begin{array}{l}1.004^{* *} \\
(3.71)\end{array}$ & $\begin{array}{l}1.003 * * * \\
(2.73)\end{array}$ & - & $\begin{array}{l}1.004 * * * \\
(3.74)\end{array}$ & $\begin{array}{l}-.997 \\
(0.85)\end{array}$ & $\begin{array}{l}-.996 \\
(0.93)\end{array}$ & - & $\begin{array}{l}-.997 \\
(0.80)\end{array}$ \\
\hline Binge drinker & - & $\begin{array}{l}3.76 * * \\
(2.32)\end{array}$ & $\begin{array}{l}4.62 * * * \\
(2.69)\end{array}$ & - & - & $\begin{array}{l}1.24 \\
(0.56)\end{array}$ & $\begin{array}{l}1.09 \\
(0.23)\end{array}$ & - \\
\hline $\begin{array}{l}\text { Min. wage as } \% \\
\text { of average wage }\end{array}$ & - & - & - & $\begin{array}{l}-0.88 \\
(0.88)\end{array}$ & - & - & - & $\begin{array}{l}-.783 * \\
(1.77)\end{array}$ \\
\hline No. died & 25 & 25 & 25 & 25 & 49 & 49 & 49 & 49 \\
\hline $\mathrm{N}$ & 5862 & 5862 & 5862 & 5862 & 5465 & 5566 & 5566 & 5465 \\
\hline Pseudo $\mathrm{R}^{2}$ & .128 & .149 & .134 & .130 & .212 & .210 & .211 & .219 \\
\hline
\end{tabular}

Coefficients are reported as odds ratios. Z-statistics in parentheses. Standard errors are calculated using the Huber/White method and are corrected for individual clustering. All regressions include controls for marital status, education level, year of the survey, and large region (North, Central, Volga, North Caucuses, Urals, West Siberia, East Siberia, Moscow/St. Petersburg). A binge drinker is defined as someone who reports their 'usual' alcohol consumption in the last 30 days as 120 grams or more of hard alcohol per day.

*** Statistically significant at the 1 percent level or less. 
** Statistically significant at the 5percent level or less.

* Statistically significant at the 10 percent level or less 
Appendix Figure 1. Male and Female Life Expectancy at Birth, All Transition Countries

A. Baltic Republics

Men

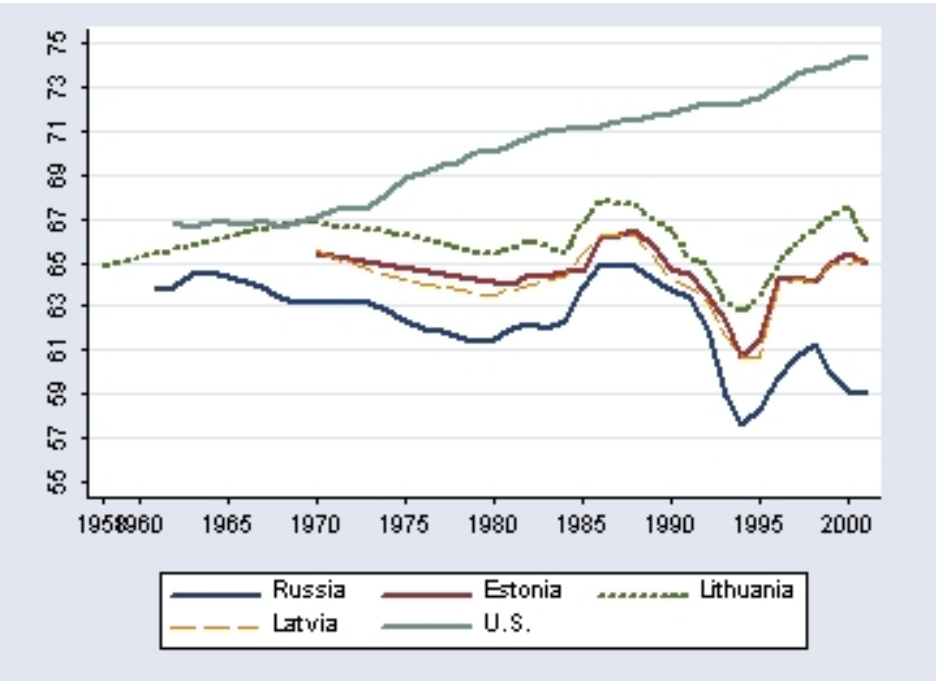

Women

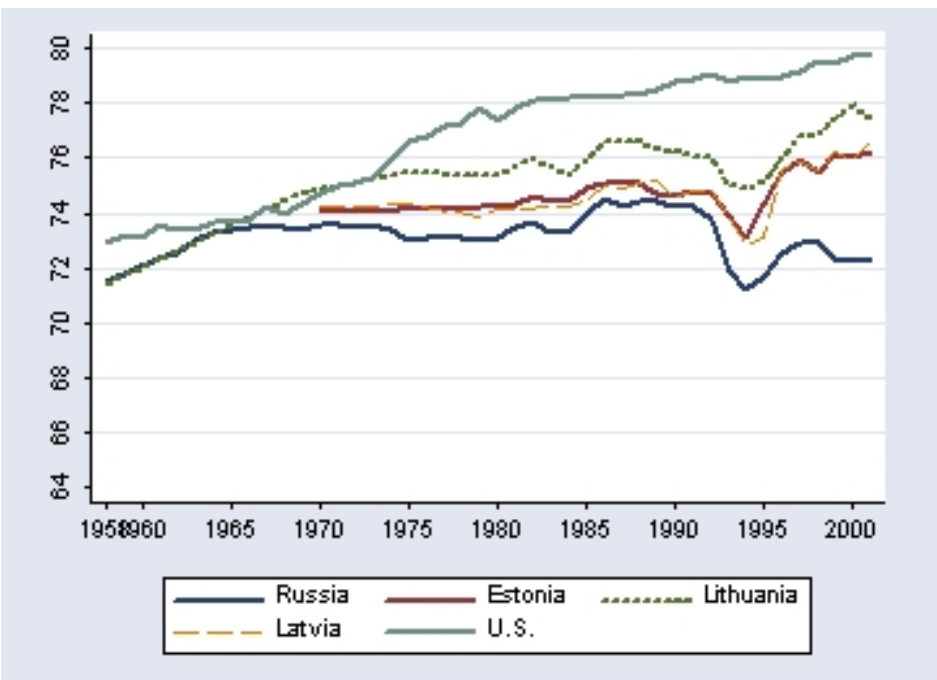

B. Western Former Soviet Union

Men

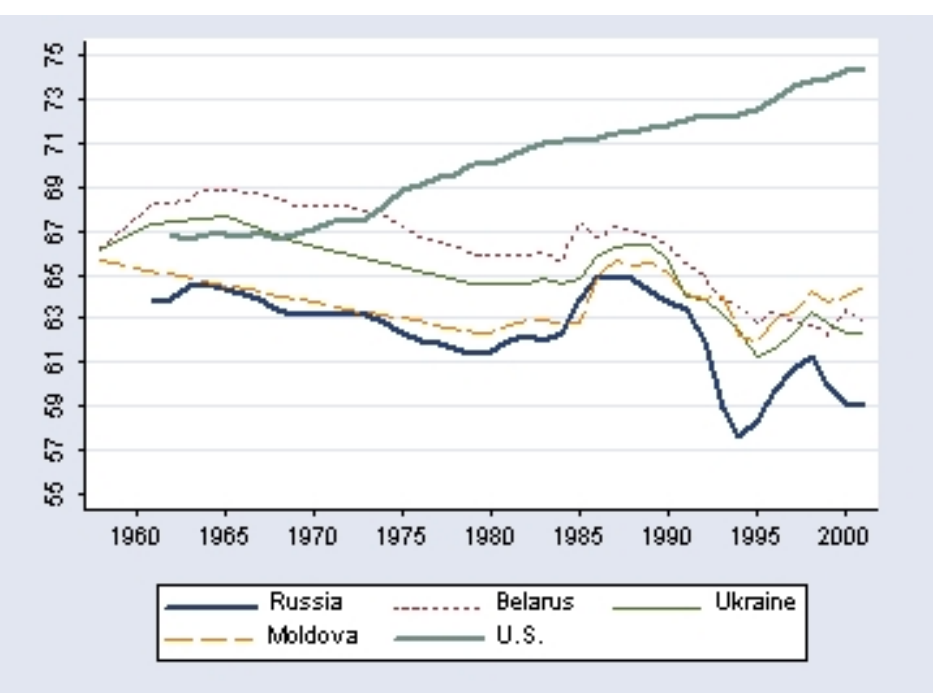

Women

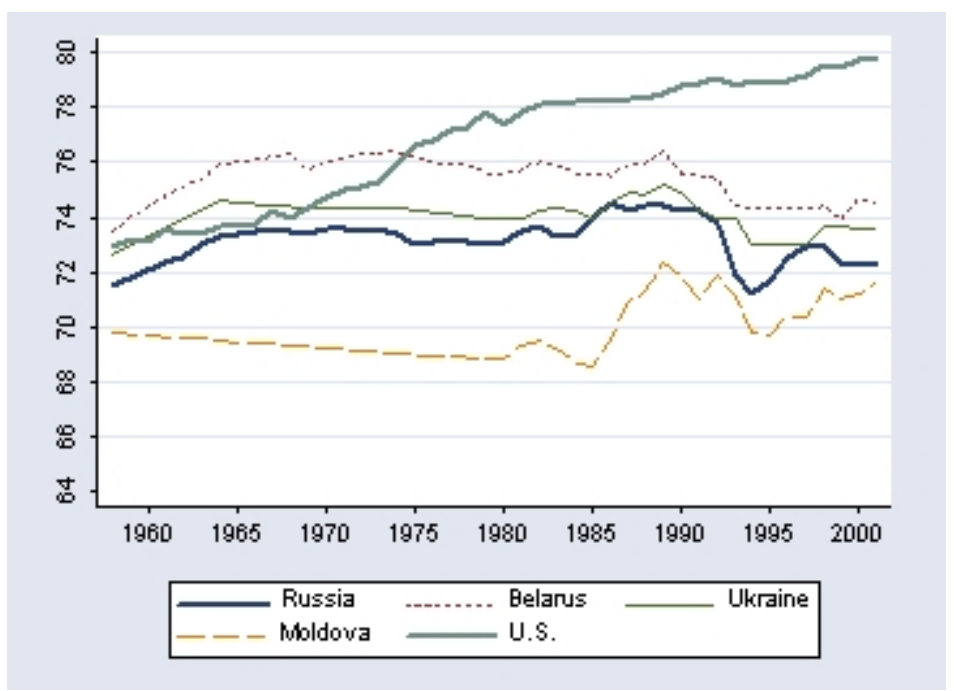


Men

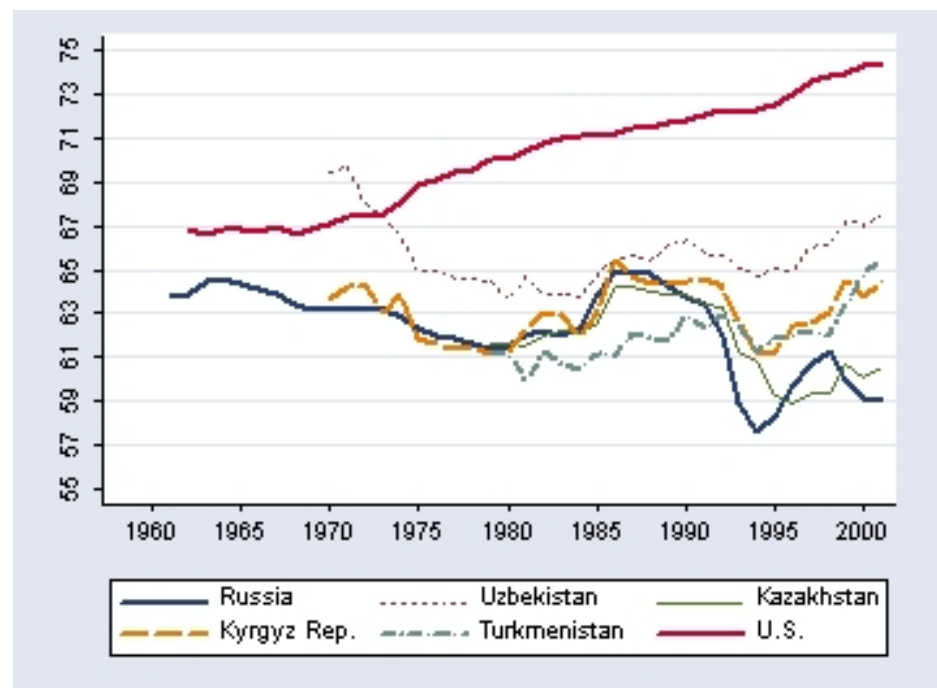

Women

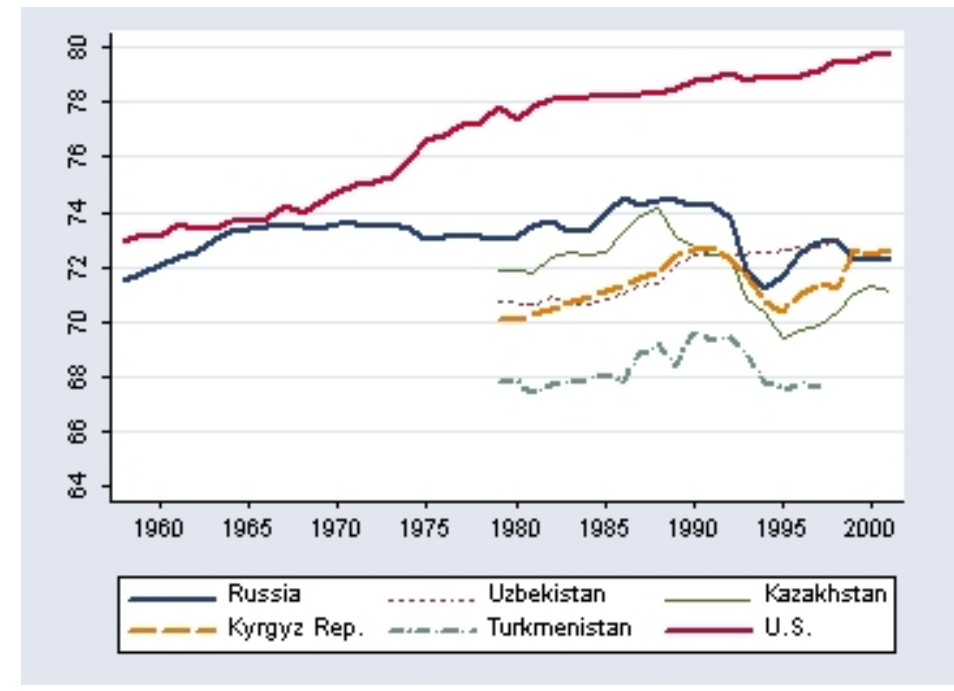

D. Caucuses

\section{Men}

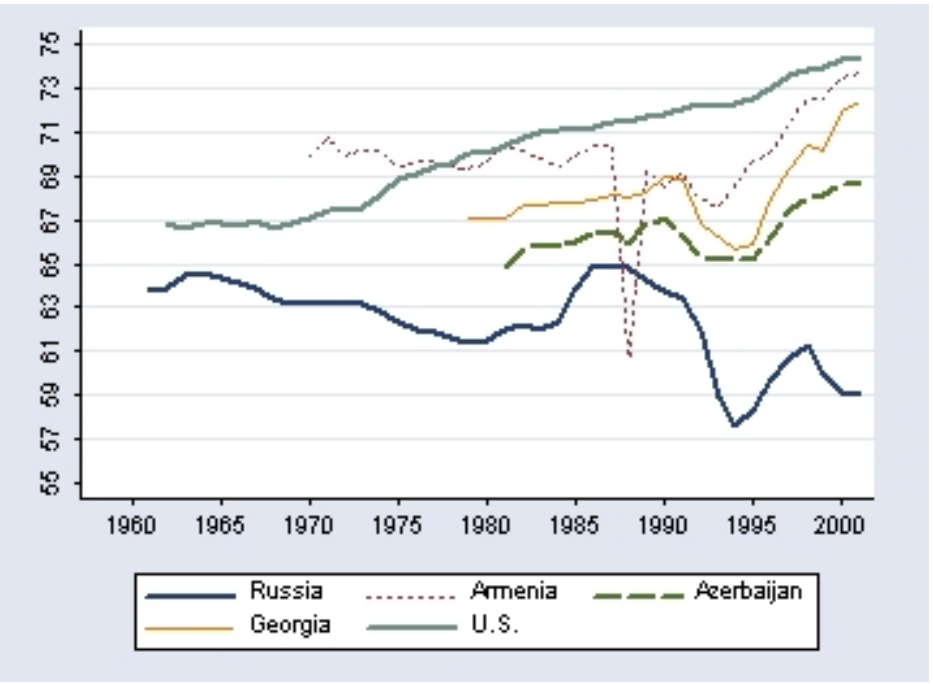

\section{Women}

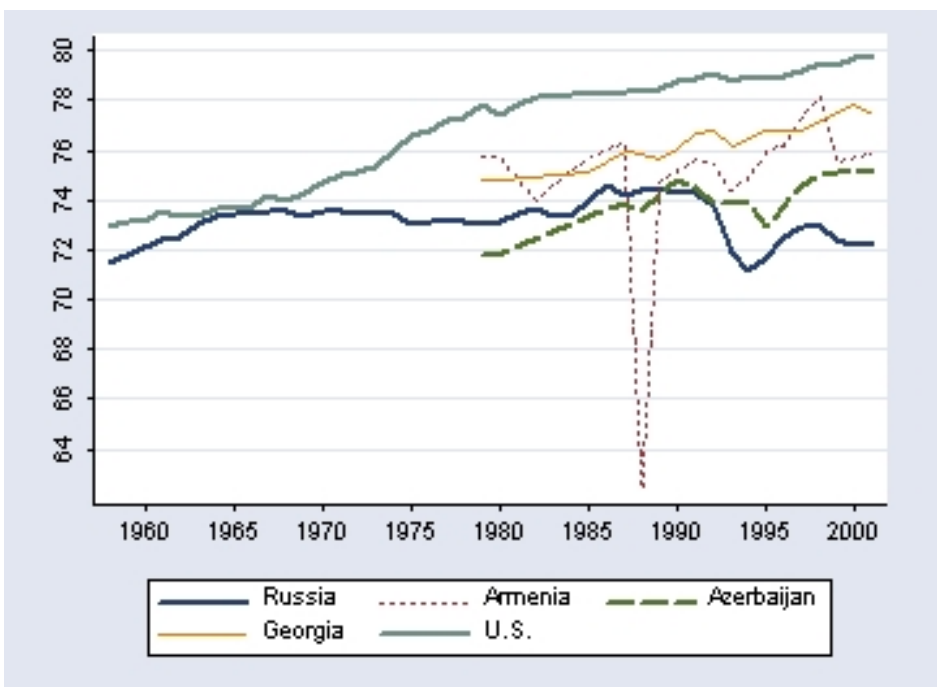




\section{E. Central Europe}

Men

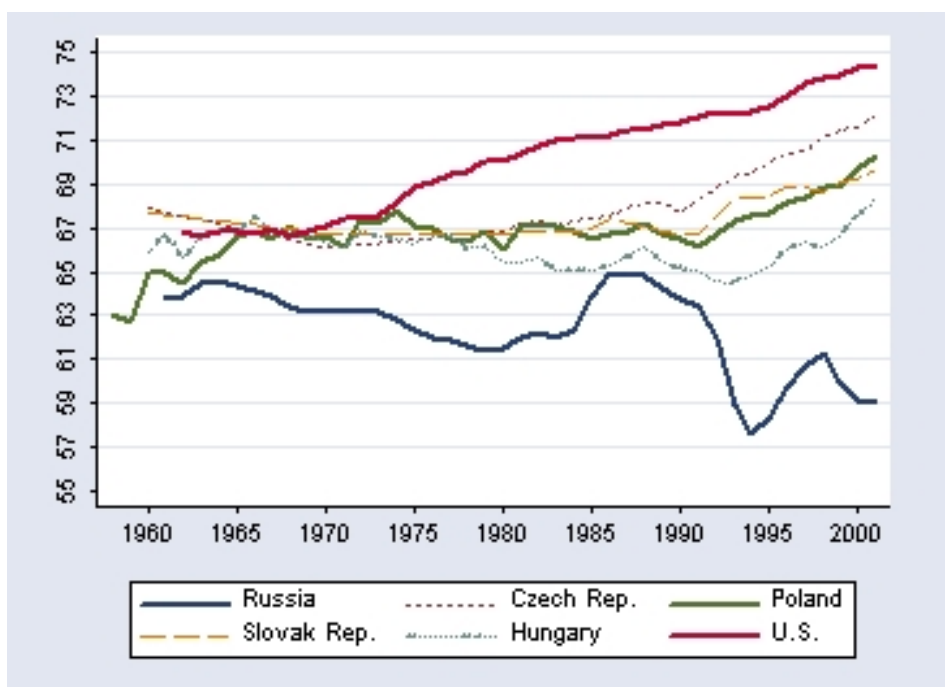

Women

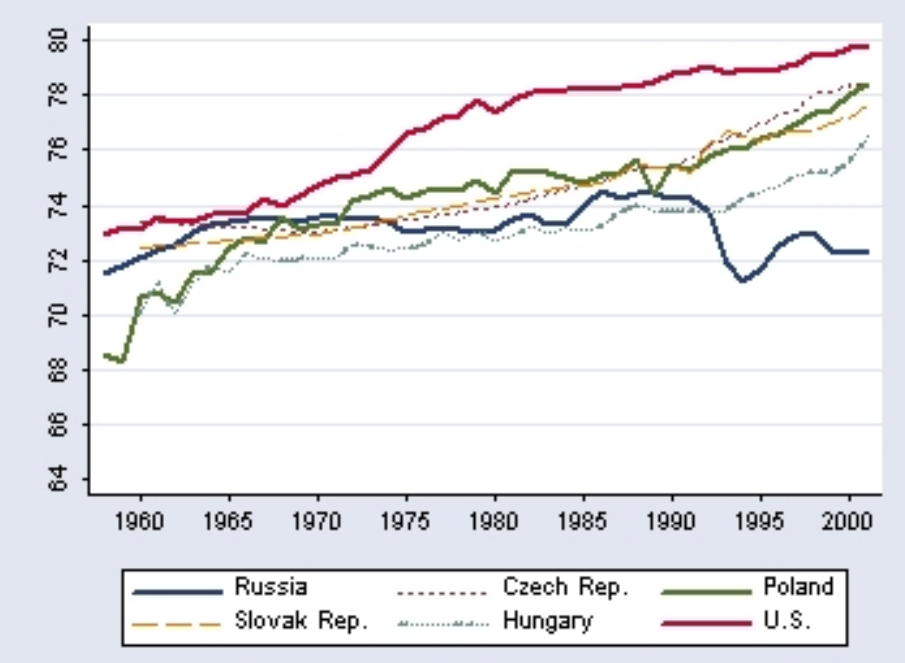

\section{Men}

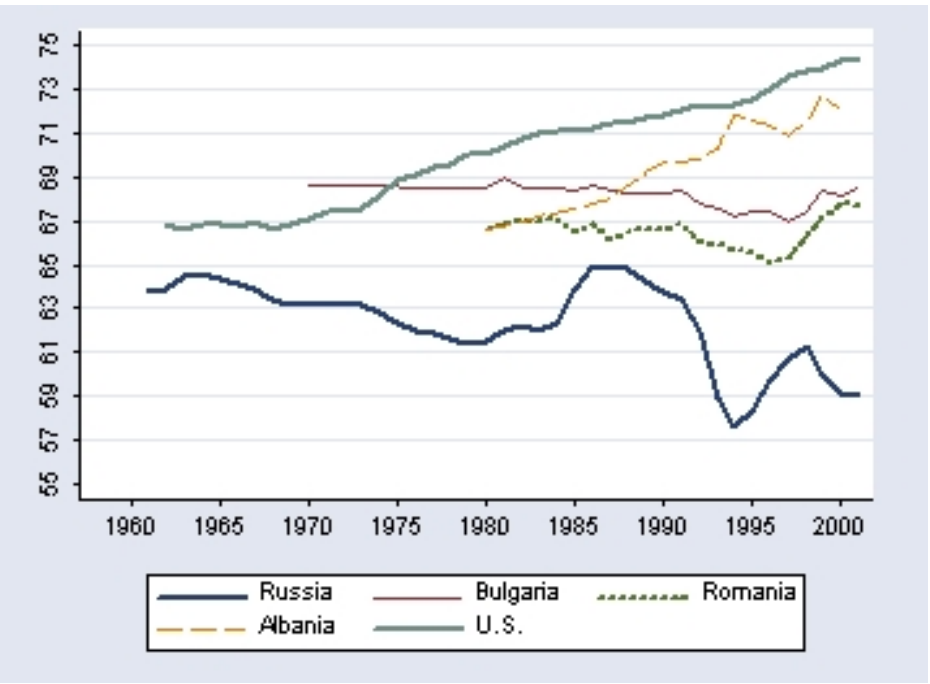

\section{Women}

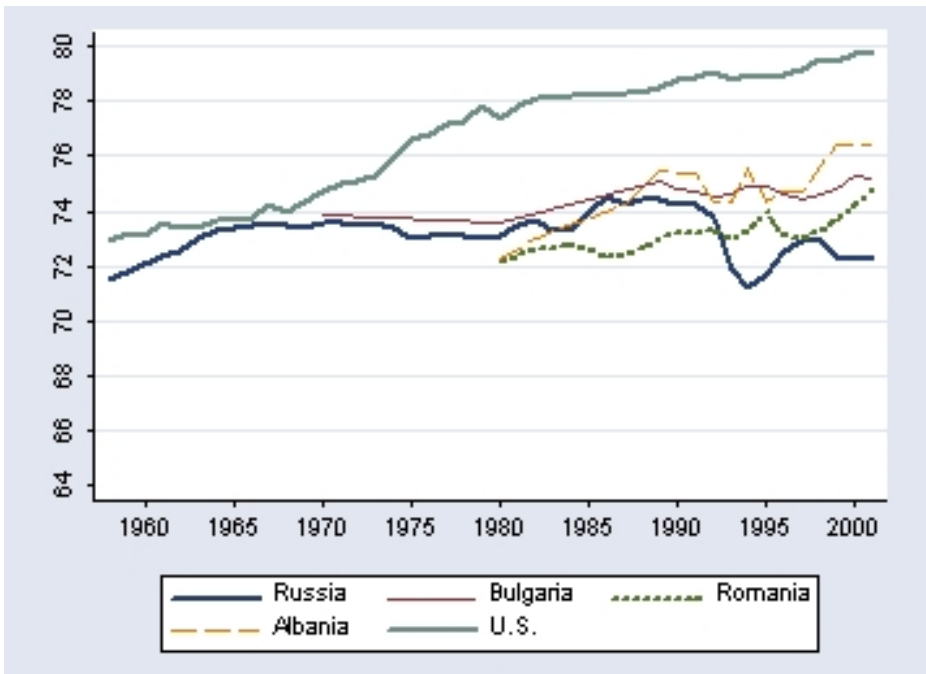




\section{G. Former Yugoslavia}

Men

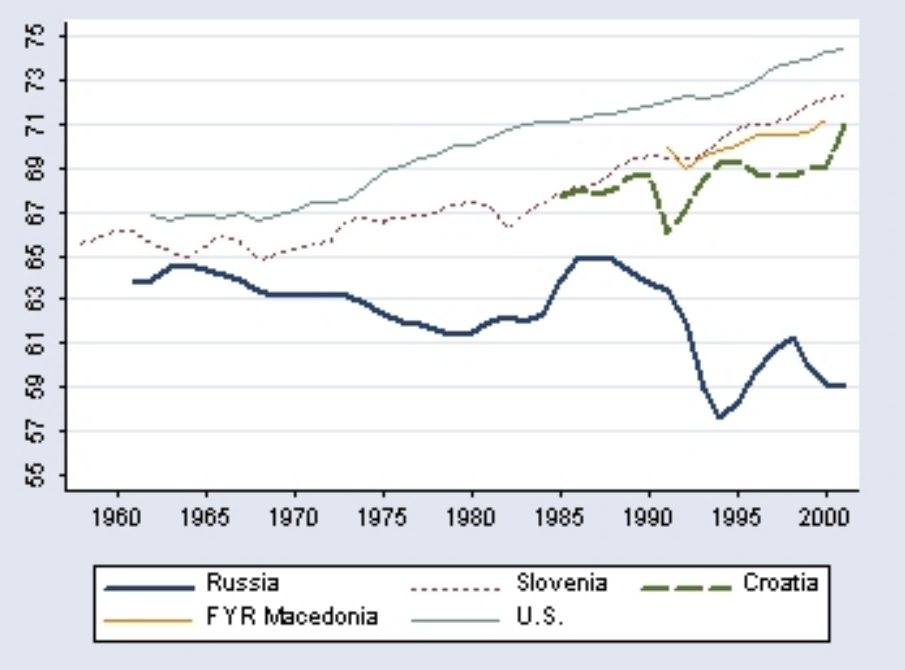

Women

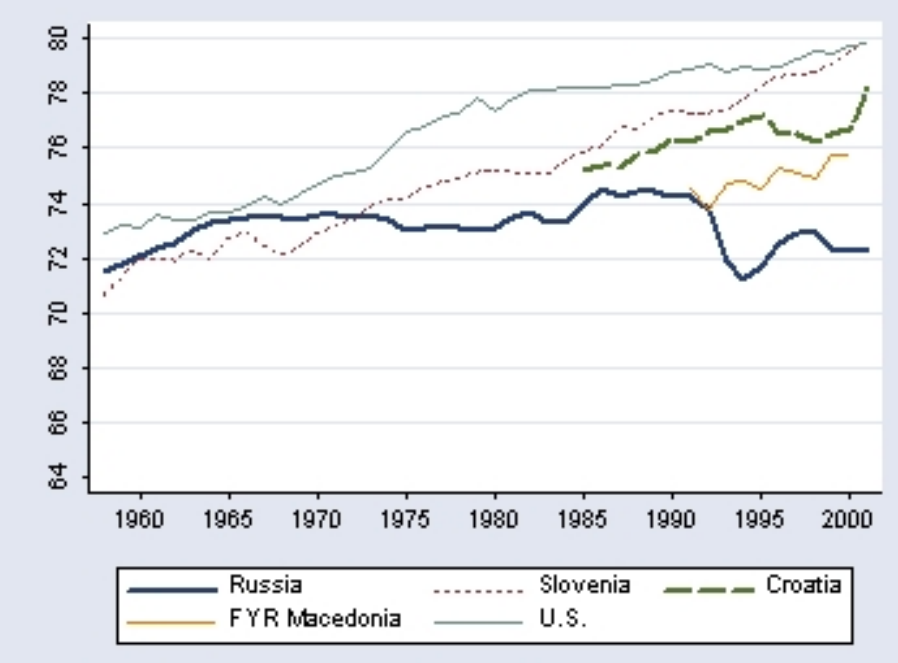


Appendix Figure 2. Per Capita Alcohol Consumption, Selected Countries, Official Measure

A. Baltic Republics

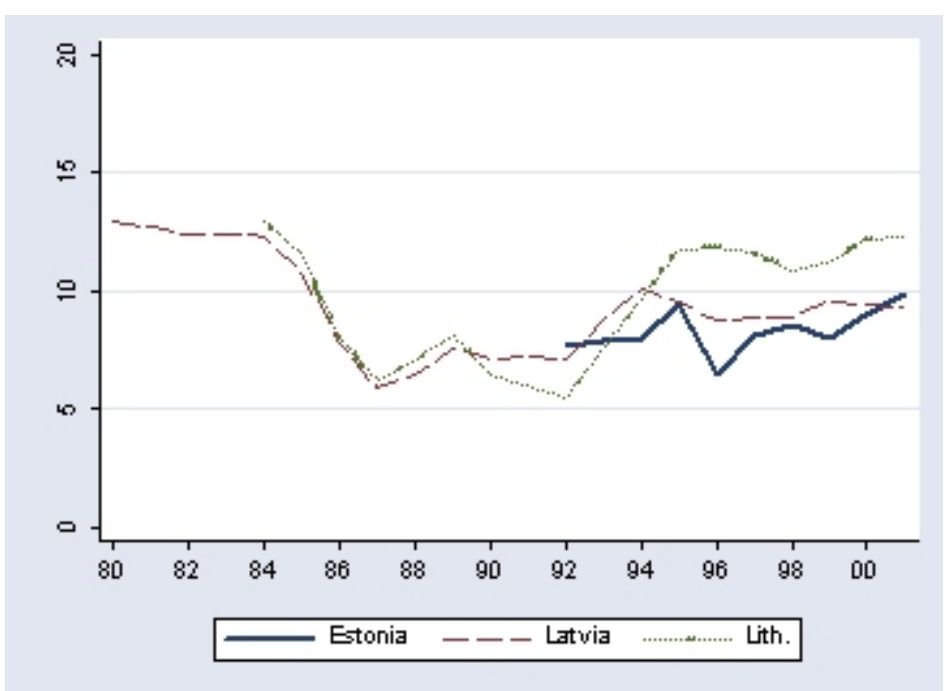

C. Central Europe

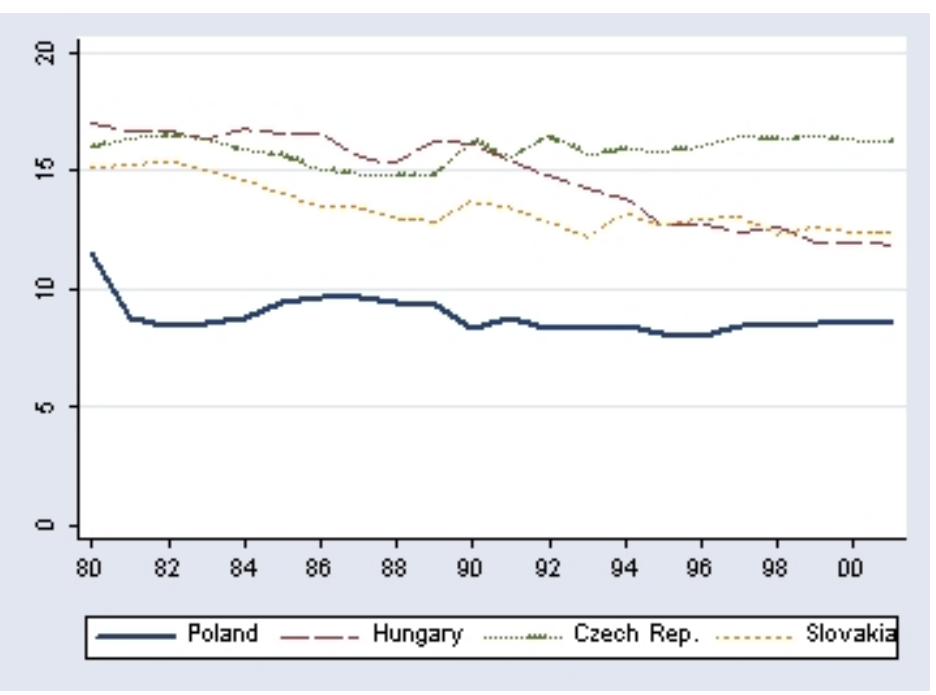

B. European Former Soviet Union

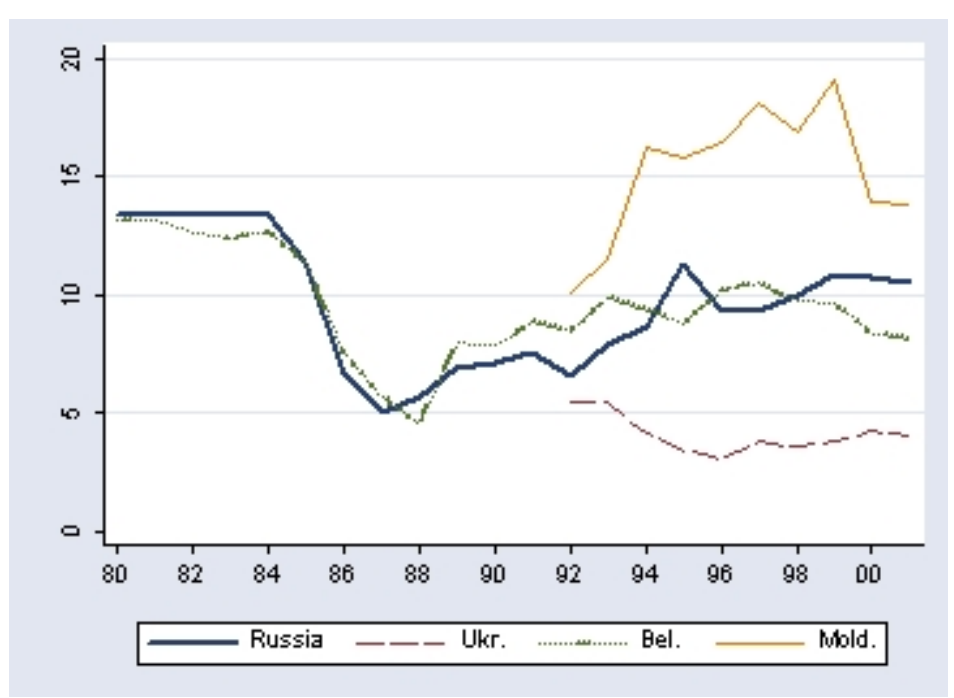

D. Southern Europe and Slovenia

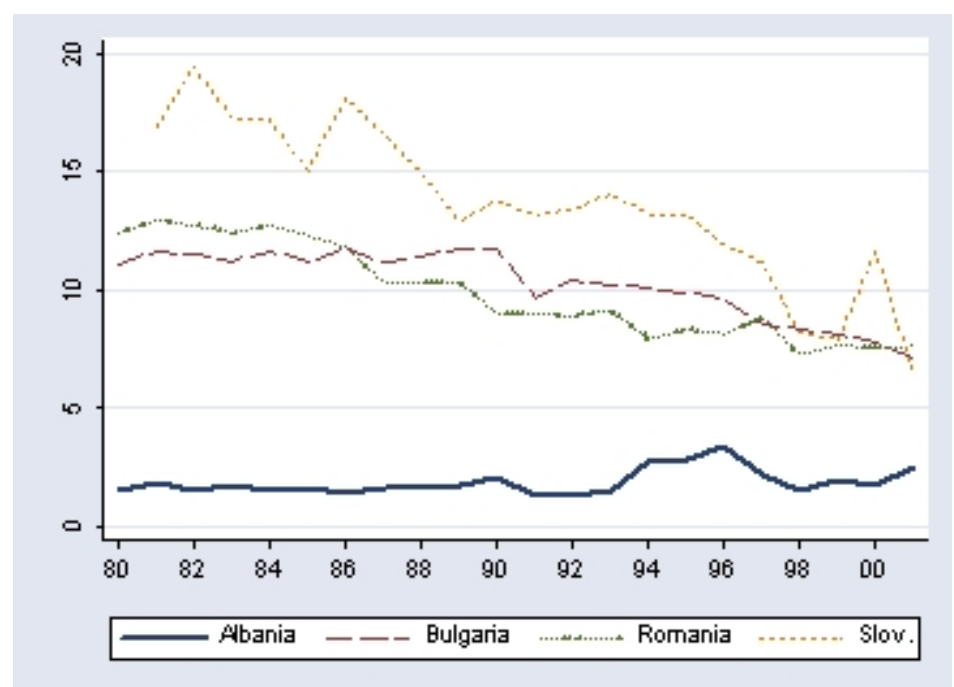




\section{Appendix Table 1. Logistic Regressions for Women Age 18 and Over Dying in the \\ Russian Longitudinal Monitoring Survey, 1994-2002 \\ [dependent variable: dummy variable for whether the person died]}

\begin{tabular}{|c|c|c|c|c|c|c|}
\hline $\begin{array}{l}\text { Independent } \\
\text { variable }\end{array}$ & (1) & (2) & (3) & (4) & (5) & (6) \\
\hline Age & $\begin{array}{l}1.09 * * * \\
(12.5)\end{array}$ & $\begin{array}{l}1.09 * * * \\
(12.4)\end{array}$ & $\begin{array}{l}1.09 * * * \\
(12.3)\end{array}$ & $\begin{array}{l}1.09 * * * \\
(12.4)\end{array}$ & $\begin{array}{l}1.09 * * * \\
(12.3)\end{array}$ & $\begin{array}{l}1.09 * * * \\
(12.4)\end{array}$ \\
\hline $\begin{array}{l}\text { Log(income per } \\
\text { capita) }\end{array}$ & $\begin{array}{l}-.842 * * \\
(2.44)\end{array}$ & $\begin{array}{l}-.842 * * \\
(2.44)\end{array}$ & $\begin{array}{l}-.843 * * \\
(2.43)\end{array}$ & $\begin{array}{l}-.843 * * \\
(2.43)\end{array}$ & $\begin{array}{l}-.845^{* *} \\
(2.37)\end{array}$ & $\begin{array}{l}-.847 * * \\
(2.34)\end{array}$ \\
\hline $\begin{array}{l}\text { Poor health } \\
(1=\text { yes })\end{array}$ & $\begin{array}{l}1.91 * * * \\
(3.75)\end{array}$ & $\begin{array}{l}1.91 * * * \\
(3.75)\end{array}$ & $\begin{array}{l}1.88 * * * \\
(3.67)\end{array}$ & $\begin{array}{l}1.88 * * * \\
(3.67)\end{array}$ & $\begin{array}{l}1.89 * * * \\
(3.71)\end{array}$ & $\begin{array}{l}1.92 * * * \\
(3.77)\end{array}$ \\
\hline BMI & $\begin{array}{l}-.942 * * * \\
(3.87)\end{array}$ & $\begin{array}{l}-.942 * * * \\
(3.87)\end{array}$ & $\begin{array}{l}-.942 * * * \\
(3.89)\end{array}$ & $\begin{array}{l}-.942 * * * \\
(3.89)\end{array}$ & $\begin{array}{l}-.941 * * * \\
(3.89)\end{array}$ & $\begin{array}{l}-.943 * * * \\
(3.82)\end{array}$ \\
\hline BMI squared & $\begin{array}{l}1.00 * * * \\
(3.20)\end{array}$ & $\begin{array}{l}1.00 * * * \\
(3.20)\end{array}$ & $\begin{array}{l}1.00 * * * \\
(3.21)\end{array}$ & $\begin{array}{l}1.00 * * * \\
(3.21)\end{array}$ & $\begin{array}{l}1.00 * * * \\
(3.24)\end{array}$ & $\begin{array}{l}1.00 * * * \\
(3.15)\end{array}$ \\
\hline $\begin{array}{l}\text { Ever had a heart } \\
\text { attack }\end{array}$ & $\begin{array}{c}1.14 \\
(0.46)\end{array}$ & $\begin{array}{l}1.14 \\
(0.46)\end{array}$ & $\begin{array}{c}1.12 \\
(0.42)\end{array}$ & $\begin{array}{l}1.13 \\
(0.42)\end{array}$ & $\begin{array}{c}1.12 \\
(0.40)\end{array}$ & $\begin{array}{l}1.14 \\
(0.47)\end{array}$ \\
\hline Diabetic & $\begin{array}{c}1.30 \\
(1.20)\end{array}$ & $\begin{array}{c}1.30 \\
(1.20)\end{array}$ & $\begin{array}{c}1.29 \\
(1.16)\end{array}$ & $\begin{array}{c}1.29 \\
(1.16)\end{array}$ & $\begin{array}{c}1.29 \\
(1.18)\end{array}$ & $\begin{array}{c}1.30 \\
(1.20)\end{array}$ \\
\hline Ever had a stroke & $\begin{array}{l}2.18 * * * \\
(2.99)\end{array}$ & $\begin{array}{l}2.18 * * * \\
(2.99)\end{array}$ & $\begin{array}{l}2.16 * * * \\
(2.96)\end{array}$ & $\begin{array}{l}2.16^{* * * *} \\
(2.96)\end{array}$ & $\begin{array}{l}2.21 * * * \\
(3.04)\end{array}$ & $\begin{array}{l}2.18^{* * * *} \\
(2.99)\end{array}$ \\
\hline Smoker & $\begin{array}{l}2.87 * * * \\
(3.29)\end{array}$ & $\begin{array}{l}2.85 * * * \\
(3.28)\end{array}$ & $\begin{array}{l}3.17 * * * \\
(3.43)\end{array}$ & $\begin{array}{l}3.19 * * * \\
(3.45)\end{array}$ & $\begin{array}{l}2.94 * * * \\
(3.41)\end{array}$ & $\begin{array}{l}2.65 * * * \\
(3.05)\end{array}$ \\
\hline $\begin{array}{l}\text { Alcohol } \\
\text { consumption }\end{array}$ & - & $\begin{array}{r}1.001 \\
(0.46)\end{array}$ & $\begin{array}{l}1.002 * * \\
(2.29)\end{array}$ & - & $\begin{array}{r}1.001 \\
(0.53)\end{array}$ & $\begin{array}{r}1.001 \\
(0.26)\end{array}$ \\
\hline Binge drinker & - & - & $\begin{array}{r}-.509 * \\
(1.71)\end{array}$ & $\begin{array}{l}-.541 \\
(1.58)\end{array}$ & - & - \\
\hline $\begin{array}{l}\text { Positive } \\
\text { expectations }\end{array}$ & - & - & - & - & $\begin{array}{l}-.491 * * \\
(1.98)\end{array}$ & \\
\hline $\begin{array}{l}\text { Unemployed in } \\
\text { previous period }\end{array}$ & - & - & - & - & - & $\begin{array}{c}2.01 \\
(1.60)\end{array}$ \\
\hline $\begin{array}{l}\text { On unpaid leave } \\
\text { in prev. period }\end{array}$ & - & - & - & - & - & $\begin{array}{l}1.76 \\
(0.93)\end{array}$ \\
\hline No. died & 308 & 308 & 308 & 308 & 308 & 308 \\
\hline $\mathrm{N}$ & 21091 & 21091 & 21091 & 21091 & 21091 & 21091 \\
\hline Pseudo $\mathrm{R}^{2}$ & .283 & .283 & .284 & .284 & .285 & .284 \\
\hline
\end{tabular}

Coefficients are reported as odds ratios. Z-statistics in parentheses. Standard errors are calculated using the Huber/White method and are corrected for individual clustering. All regressions include controls for marital status, education level, year of the survey, and large region (North, Central, Volga, North 
Caucuses, Urals, West Siberia, East Siberia, Moscow/St. Petersburg). A binge drinker is defined as someone who reports their 'usual' alcohol consumption in the last 30 days as 120 grams or more of hard alcohol per day.

*** Statistically significant at the 1 percent level or less.

** Statistically significant at the 5 percent level or less.

* Statistically significant at the 10 percent level or less. 